\title{
Poultry in Motion: A Study of International Trade Finance Practices
}

\section{Citation}

Antras, Pol, and C. Fritz Foley. "Poultry in Motion: A Study of International Trade Finance

Practices." Journal of Political Economy (forthcoming).

\section{Permanent link}

http://nrs.harvard.edu/urn-3:HUL.InstRepos:13244612

\section{Terms of Use}

This article was downloaded from Harvard University's DASH repository, and is made available under the terms and conditions applicable to Open Access Policy Articles, as set forth at http:// nrs.harvard.edu/urn-3:HUL.InstRepos:dash.current.terms-of-use\#OAP

\section{Share Your Story}

The Harvard community has made this article openly available.

Please share how this access benefits you. Submit a story.

Accessibility 


\title{
Poultry in Motion: A Study of International Trade Finance Practices
}

\author{
Pol Antràs and C. Fritz Foley*
}

May 2014

\begin{abstract}
This paper analyzes the financing terms that support international trade and sheds light on how these terms shape the impact of economic shocks on trade. Analysis of transaction-level data from a U.S.-based exporter of frozen and refrigerated food products, primarily poultry, reveals broad patterns about the use of alternative financing terms. These patterns help discipline a model in which the choice of trade finance terms is shaped by the risk that an importer defaults on an exporter and by the possibility that an exporter does not deliver goods as specified in the contract. The empirical results indicate that cash in advance and open account terms are much more commonly used than letter of credit and documentary collection terms. Transactions are more likely to occur on cash in advance or letter of credit terms when the importer is located in a country with weak contractual enforcement. As an importer develops a relationship with the exporter, transactions are less likely to occur on terms that require prepayment. During the recent crisis, the exporter was more likely to demand cash in advance terms when transacting with new customers, and customers that traded on cash in advance and letter of credit terms prior to the crisis decreased their purchases by $17.3 \%$ more than other customers. The model illustrates that these findings can be rationalized if (i) misbehavior on the part of the exporter is of little concern to importers, and (ii) local banks in importing countries are more effective than the exporter in pursuing financial claims against importers.
\end{abstract}

\footnotetext{
${ }^{*}$ Harvard University and NBER; Harvard Business School and NBER. The authors are very grateful to numerous employees at the anonymous firm that provided the data and to Matthew Johnson and James Zeitler for excellent research assistance. We also thank Kyle Bagwell, Mihir Desai, Ricard Gil, James Hines, Kalina Manova, Sam Kortum (the editor), Mitchell Petersen, Tim Schmidt-Eisenlohr, Bill Simpson, Andrei Shleifer, Bob Staiger, Catherine Thomas, three anonymous referees, and seminar participants at the AEA meetings, Boston University, the Boston Federal Reserve, Columbia, Duke, Harvard, LSE, Manheim, MIT Sloan, the NBER CF Program Meetings, the NBER ITI Program Meetings, Nottingham, NYU Stern, Oxford, the University of British Columbia, Universidad de Alicante, Universitat de València, and the University of Missouri for helpful comments. Foley thanks the Division of Research of the Harvard Business School for financial support. Other work also uses the phrase "Poultry in Motion," including the album by Hasil Adkins and the film "Chicken Run."
} 


\section{Introduction}

Managers at firms that engage in international trade must decide which financing terms to use in their transactions. An exporter can require the importer to pay for goods before they are loaded for shipment, can allow the importer to pay at some time after the goods have arrived at their destination, or can use some form of bank intermediation such as a letter of credit. Alternative terms are associated with distinct risks and capital requirements for traders, and they give rise to cross-border capital flows and financial claims. Although similar claims arise for purely domestic transactions, international transactions are unique because longer transportation times often increase working capital requirements and variation in institutional context across countries introduces additional considerations. How do cross-country differences in contractual enforcement affect the terms that are selected? Can the development of a relationship between traders mitigate concerns associated with weak institutional environments? How does the manner in which trade is financed shape the impact of shocks like the recent crisis on trade flows? This paper sheds light on the relative use of different kinds of financing terms and addresses these questions.

One of the main challenges in studying the financing arrangements used to support international trade is that detailed data on how transactions are financed are not readily available. This paper begins by presenting some broad patterns that emerge from analyzing detailed data on the activities of a single U.S.-based firm that exports frozen and refrigerated food products, primarily poultry. The data cover roughly $\$ 7$ billion in sales to more than 140 countries over the 1996-2009 period and contain comprehensive information on the financing terms used in each transaction.

Three main facts emerge from this initial exploration. First, the most commonly used financing terms do not involve direct financial intermediation by banks. They are cash in advance terms and open account terms; these are used for $42.4 \%$ and $41.3 \%$ of the value of transactions, respectively. Cash in advance terms require the importer to pay before goods are shipped and title is transferred. Open account terms allow a customer to delay payment until a certain time following receipt of the goods. Over the sample period, $5.5 \%$ of the value of transactions occur on letter of credit terms and $10.7 \%$ on documentary collection terms. Under both of these terms, banks intermediate payments. ${ }^{1}$

The second stylized fact that emerges from the data is that the location of the importer has a large impact on the financing terms that are used. Sales to locations with weak contractual enforcement are more likely to occur on cash in advance terms than sales to other locations. This pattern holds for a variety of measures of contractual enforcement, and the differences are large. For example, $63.8 \%$ of exports to countries with a civil law legal origin occur on cash in advance terms, but only $4.0 \%$ of exports to countries with a common law legal origin do. ${ }^{2}$

\footnotetext{
${ }^{1}$ In typical transactions financed with a letter of credit, a bank commits to pay for goods on behalf of the importer provided the goods are shipped as specified, and this commitment is made before goods are shipped. Under the most commonly used documentary collection terms, which are sight draft terms, the exporter's bank only releases title to the traded goods to the importer's bank when the importer's bank pays the associated draft, and this exchange typically occurs when goods arrive at the importer's location. Foley, Johnson, and Lane (2010) describe these terms in detail.

${ }^{2}$ Common and civil law legal traditions represent alternative approaches to exerting control over economic life
} 
The third main fact is that as the exporter establishes a relationship with an importer through repeated interaction, transactions are less likely to occur on cash in advance terms. As the level of cumulative transactions with a customer increases from values of less than $\$ 25,000$ to more than $\$ 5$ million, the share of transactions that occur on cash in advance terms falls from $59.4 \%$ to $10.7 \%$.

These empirical patterns are used to motivate a model of how trade is financed. The mode of financing chosen by firms in the model is shaped by cross-country differences in contractual enforcement. In particular, there are two fundamental sources of contractual frictions: first, the importer may default and not pay fully for goods it orders, and second, the exporter may not produce and deliver goods as specified. Trading partners choose to trade on cash in advance terms; post shipment terms, which include documentary collection and open account terms; or letter of credit terms. In post shipment term transactions, because of default risk, exporters expect lower revenues relative to those stated in the sales contract when transacting with customers that are in environments where contracts are enforced with a lower probability and in environments that are further away. Cash in advance terms eliminate this default risk, but under these terms, importers might have concerns about the quality of goods being shipped and are required to pay funding costs that might be high. Finally, letters of credit reduce the problem of exporter misbehavior and also eliminate importer default risk, but these instruments are associated with high bank fees.

The model identifies a key condition under which exports to locations characterized by weak contractual enforcement are more likely to occur on cash in advance or letter of credit terms as opposed to other terms. Namely, this requires that local banks in the importing country be better able than exporters to pursue financial claims against importers. This condition is plausible given that such banks are likely to be familiar with and close to importers. Regardless of this condition, the model predicts that the effects of contractual enforcement on financing terms is more pronounced for sales to customers located further away from the exporter. The theory also predicts that the use of a letter of credit is unlikely to be optimal whenever the exporter's scope for misbehavior is limited, a plausible scenario in the empirical setting considered.

In order to analyze the impact of the development of relationships between traders, a dynamic extension of the theoretical framework considers the possibility that some fraction of importers is trustworthy and always honors a contract and the remaining fraction is not always trustworthy. With a certain probability, these latter traders face a liquidity shock and do not honor a contract when it is not enforced. In this set up, the exporter learns which importers are trustworthy and offers post shipment terms as a trading relationship develops. Introducing these features allows the model to shed light on the impact of the recent economic crisis. This crisis can be mapped to the model as an increase in the likelihood that importers face liquidity shocks and also as a decrease in demand. When these events occur, new customers are more likely to trade with the exporter on cash in advance terms, and importers that were trading with the exporter on such terms before the

that were established by the 19th century and then spread throughout the world. Common law tends to promote market outcomes by protecting private property and contract rights. Civil law is more concerned with market failures and supports state-desired allocations in ways that can attenuate the strength of private contracts. See La Porta, Lopez-de-Silanes, and Shleifer (1998, 2008). 
shock are the ones that reduce their purchases the most.

Regression analysis explores the robustness of the basic empirical facts described above and tests other predictions generated by the model. Results of multinomial logit specifications that explain the choice of financing terms indicate that cash in advance terms and letter of credit terms are each more frequently used for sales to destinations where contracts are less likely to be honored. Specifications that include measures of contractual enforcement interacted with distance show that proximity reduces the effects of weak contractual enforcement. Tests that include fixed effects for each customer reveal that as a customer develops a relationship with the exporter, they trade on cash in advance terms less frequently and on post shipment terms more frequently.

The data also inform the impact of the recent economic crisis. Customers that began to trade with the exporter during the October 2008 to June 2009 period were more likely to trade on cash in advance terms than customers that started to trade with the exporter during other periods. Customers that traded on cash in advance terms prior to the crisis reduced their purchases by larger amounts than those that had traded on post shipment terms. Differences in performance are large. Estimates imply that between the first three quarters of 2008 and the subsequent three quarters customers that do not make use of post shipment terms decreased sales by 17.3 percentage points more than customers that only used such terms.

Taken together, this analysis of the financing of trade reaches three main conclusions. First, to engage in trade, firms that are likely to have the most difficult time obtaining capital appear to be the ones that are most likely to need it. Firms located in countries with weak enforcement of contracts typically finance transactions, yet external capital is often very costly in such environments. This insight contributes to the literature that considers how institutional development affects cross-border financing decisions and trade. Previous work illustrates how institutions that facilitate access to capital give rise to comparative advantage in sectors that require external finance. ${ }^{3}$ Existing work also analyzes how firms adjust their operating, financing, and investment decisions in response to general problems of contract enforcement and to more specific problems that make financial contracting costly. ${ }^{4}$

The second conclusion is that as a trading relationship develops, it can be a source of capital for firms in countries with poorly functioning institutions. ${ }^{5}$ Put differently, the establishment of trading relationships overcomes concerns about the enforcement of contracts and allows capital to flow to places where it is needed. In making this point, the paper contributes to research that considers how relationships and experience can substitute for weak institutions. ${ }^{6}$ Papers in this

\footnotetext{
${ }^{3}$ Papers that develop this idea include Kletzer and Bardhan (1987), Beck (2002), Chaney (2005), Manova (2008, 2013), and Antràs and Caballero (2009).

${ }^{4}$ Antràs (2003, 2005), Antràs and Helpman (2004, 2008), Levchenko (2007), and Nunn (2007) analyze the impact of contractual enforcement on trade flows and ownership structure. Desai, Foley, and Hines (2004) and Antràs, Desai, and Foley (2009) study the impact of costly financial contracting on firm decisions.

${ }^{5}$ A substantial literature seeks to understand trade credit, or the financial relationships between firms that have supply relationships. Much of this work emphasizes the idea that firms have access to better collateral or private information as a consequence of interacting in product markets. Burkart and Ellingsen (2004), Cuñat (2007), Giannetti, Burkart, and Ellingsen (2011), Klapper, Laeven, and Rajan (2012), Petersen and Rajan (1997), and Ng, Smith, and Smith (1999) represent recent work in this field.

${ }^{6}$ Papers that make this point include Milgrom, North, and Weingast (1990), Greif (1993), McMillan and Woodruff
} 
literature consider how relational mechanisms allow contracting without formal legal protections. Analyses also consider the ways in which trust and the development of networks facilitate trade and cross-border investment. ${ }^{7}$

Third, the results imply that the impact of shocks to demand and the liquidity of trading partners is shaped by how trade is financed. The theory and the data indicate that sales to customers that were trading with the exporter on cash in advance terms experience the largest decline during downturns like the recent economic crisis. As such, the paper adds to work analyzing how trade responds to macroeconomic shocks and changes in access to capital. ${ }^{8}$

Other related recent work provides insights about the financing of international trade. Much of this work is theoretical and does not make use of detailed transaction level data that indicate when different financing terms are used. The static version of the model developed below is similar to the one in Schmidt-Eisenlohr (2013). The dynamic extension of the model described below shares features with the model in Araujo and Ornelas (2007), which however does not address trade finance directly. Olsen (2013) also considers how repeated interaction influences the choice of financing terms, and it emphasizes how letters of credit provide a valuable financing alternative when the reputational concerns of banks exceed those of trading parties. Ahn (2011) presents a model that highlights the role of information in trade finance choices. ${ }^{9}$

Given that the analysis focuses on the activities of a single exporter, it is natural to question if the findings in the paper generalize. Trade in food is regulated in ways that limit the ability of the exporter to sell low quality goods that fail to meet health standards. Therefore, the risks concerning product quality that are alleviated by the use of post shipment terms and letter of credit terms may be less salient in the food industry than in other industries. Anecdotally, banks do not seem to place as high a collateral value on food products in letter of credit transactions as they do on commodities such as oil because food products are harder to redeploy if a transaction falls apart, and this could reduce the use of letters of credit. The exporter is large and may have more ability to set terms to its advantage than other firms. Furthermore, it is noteworthy that the exporter appears to have access to capital over the sample period. It maintained relationships with several banks, and at the time of the crisis, it had a senior secured revolving credit facility that did not mature until 2011. The response of the exporter to the crisis might have been different if it faced a liquidity shock of its own.

Surveys conducted by the Finance Credit and International Business Association (FCIB) collect

(1999), Banerjee and Duflo (2000), and Macchiavello (2010).

${ }^{7}$ See, for example, Guiso, Sapienza, and Zingales (2004, 2009) and Rauch (2001).

${ }^{8}$ Ahn (2013), Amiti and Weinstein (2011), Auboin (2009), Baldwin and Evenett (2009), Chor and Manova (2012), Eaton, Kortum, Neiman, and Romalis (2013), Levchenko, Lewis, and Tesar (2010), and Paravisini, Rappoport, Schnabl, and Wolfenzon (2012) each analyze the decline in trade during the recent crisis. Alessandria, Kaboski, and Midrigan (2010), Iacovone and Zavacka (2009), Stephens (1998), and Wang and Ronci (2006) examine earlier crises. Several of these studies consider the role of credit conditions, but none make use of detailed transaction-level data.

${ }^{9}$ Ahn (2011) motivates the use of letters of credit and points out that larger trade volumes create incentives for banks to invest in acquiring information. The results on the role of contractual enforcement discussed below do not appear be a consequence of trade volumes, while the results on the role of relationships do indicate that learning about counterparty credit risk has an effect on which financing terms are used. 
data that can be used to evaluate the representativeness of some of the activities of the exporter. The data from these surveys indicate that cash in advance and open account terms are used more predominantly than letter of credit and documentary collection terms across a variety of industries. The data also suggest that sales to destinations with weak contractual enforcement are less likely to occur on open account terms. ${ }^{10}$

The remainder of this paper is organized as follows. Section 2 describes the data employed and some general patterns that appear in the data. Sections 3 and 4 lay out a model of the financing of international trade that is motivated by these patterns and that generates several additional predictions. Section 5 presents tests of features of the theory, and Section 6 concludes.

\section{$2 \quad$ Data and Three Empirical Facts}

\subsection{Basic Characteristics of the Data}

To document patterns in how international trade is financed and to test the implications of the theory developed below, this study employs detailed data on the activities of a single U.S.-based exporter. This exporter is a marketer of frozen and refrigerated food products, primarily poultry. It does not produce the goods it sells, but it procures them from suppliers who are primarily based in the U.S. and sells them to customers located in more than 140 countries. A small fraction of its products are sold under one of its own brands, and the remainder are sold unbranded. The data are transaction-level data and cover the 1996-2009 period. Each observation in the data set covers the shipment of a product to a specific customer location. Shipments are primarily seaborne. Figure 1 presents information about the share of sales by destination region defined using the World Bank's grouping of countries into regions. Figure 2 provides information about the share of sales by broad product group.

The data include information on the date on which the sales transaction was booked and the value and weight of goods sold. Perhaps most importantly for this study, the data indicate the financing terms used for each transaction. Over the 1996-2009 period, the exporter used more than 100 different financing terms when transacting with its customers. These can be grouped into four types of terms: cash in advance terms, letter of credit terms, documentary collection terms, and open account terms. Table 1 displays the categorization of the 20 most commonly used terms that cover more than $90 \%$ of the sales in the data. Cash in advance terms typically involve a wire transfer or deposit in advance of shipping goods. Open account terms require payment within a 7-30 day period after goods arrive at the importer's location. Some less frequently used financing terms include a mix of financing arrangements, and these are categorized according to the terms that offer the most security to the exporter. For example, "50\% wire transfer in advance / $50 \%$ letter of credit" terms are classified as cash in advance terms, but such terms are rarely used.

\footnotetext{
${ }^{10}$ However, this survey is limited in the scope of questions asked, and it is only completed by a limited number of firms. Ahn (2014) also provides some useful benchmarks and reports that letters of credit account for about $5 \%$ of Colombian imports and about 10\% of Chilean exports and imports in 2011.
} 


\subsection{Three Facts about How Trade is Financed}

Three broad empirical patterns emerge from a descriptive analysis of trends in the financing terms used for different transactions. First, the fraction of the value of transactions that take place on terms involving direct financial intermediation is small. Table 2 provides information about the relative use of different financing terms for the full sample. The share of sales on cash in advance terms is $42.4 \%$, and the open account share is $41.3 \%$. Documentary collections and letters of credit account for $10.7 \%$ and $5.5 \%$ of sales, respectively. Thus, more than $90 \%$ of sales occur on cash in advance or post shipment terms, and these terms are therefore emphasized in the theoretical and empirical work that follows. Another noteworthy feature of the data is the rare use of terms involving a combination of payments before and after ownership of goods is transferred.

The second pattern in the data is that sales to destinations with weak enforcement of contracts are more likely to occur on terms that offer the exporter more security. Figure 3 displays the share of sales that occur on different terms for sales made to locations classified using four different measures of the enforcement of contracts. ${ }^{11}$ Panel A characterizes countries by whether they are common or civil law countries. Panels B, C, and D split countries according to whether their measures of contract viability, payment delay, and the enforceability of contracts are above or below sample medians. ${ }^{12}$ Within each panel, four bars with different degrees of shading are presented for each subset of countries. The unshaded bars illustrate the share of sales that occur on cash in advance terms, the lightly shaded bars illustrate the letter of credit share, the darker bars illustrate the documentary collection share, and the darkest bars illustrate the open account share.

For each of the proxies of contractual enforcement, the cash in advance share is lower and the open account share is higher where the strength of enforcement of contracts is higher. In common law countries, $4.0 \%$ of sales occur on cash in advance terms and $79.8 \%$ of sales occur on open account terms, while in civil law countries these shares are $63.8 \%$ and $20.4 \%$. Similar differences appear when the sample is split using measures of contract viability, payment delay, and the enforceability of contracts. Letters of credit and documentary collections are used much less frequently than cash in advance and open account, and differences in their use across institutional environments is small.

The third finding that emerges from a descriptive look at the data relates to relationships between traders. As a relationship with a customer develops, transactions are less likely to occur on cash in advance terms. Evidence suggestive of this is apparent in the information in Table 2 about the relative use of financing terms for customers the first time they appear in the data, excluding those that appear in 1996. 51.3\% of these new customer sales occur on cash in advance

\footnotetext{
${ }^{11}$ A large fraction of the variation in payment contracts appears to come from differences across countries as opposed to differences across customers within a country. For example, if one regresses a dummy that is equal to one for transactions involving post shipment terms on a set of country fixed effects, the R-squared of the regression is 0.7735 .

${ }^{12}$ Legal origin is identified using data from the CIA World Factbook, and this classification is available for the broadest set of countries. Contract viability is a measure of the risk of contract modification or cancellation with higher values indicating lower risks, and it is drawn from the International Country Risk Guide. Payment delay is also drawn from the International Country Risk Guide, and it measures the risk of receiving and removing payments from a country with higher values indicating lower risks. Enforceability of contracts comes from Knack and Keefer (1995), and it captures the degree to which contractual agreements are honored with higher values indicating higher enforcement.
} 
terms, $14.0 \%$ occur on letter of credit terms, $12.0 \%$ occur on sight draft terms, and $22.6 \%$ occur on open account terms. Thus, terms tend to give the exporter more security when transacting with new as opposed to repeat customers. The importance of relationships is also illustrated in Figure 4. Each bar in this figure indicates the share of transactions that occur on cash in advance terms for a particular range of values of cumulative sales to a customer that have taken place since the year the data coverage begins, 1996 . For the first $\$ 25,000$ of sales, $59.4 \%$ of transactions are cash in advance transactions, and this share falls monotonically, reaching $10.7 \%$ for sales that bring cumulative sales to values exceeding $\$ 5$ million. Although this pattern suggests that the financing terms offered to customers change as a relationship matures, it could also reflect that customers that trade on cash in advance terms may buy less. Tests below use fixed effects to illustrate that financing terms indeed appear to change for customers as they establish their trustworthiness.

One question raised by the apparent role of relationships is the question of why the exporter does not experiment with offering open account terms to new customers as part of a screening process. Several aspects of the exporter's business require a cautious approach when transacting on open account terms. Industry margins are around 3-4\%. Low margins reduce the attractiveness of offering customers open account terms on an experimental basis because the exporter could lose all of the expected revenues in a transaction if an importer defaults when transacting on these terms. Furthermore, there is significant turnover among importers. Often more than one third of customers who transacted with the exporter in one year do not do so in the subsequent year. Low margins and significant customer turnover imply substantial risks for open account transactions. In sum, using open account terms with the purpose of screening buyers does not appear to be a particularly beneficial strategy for the exporter, and as a consequence the model abstracts from this possibility.

\subsection{Representativeness of Sample}

The nature of the data raise the question of whether the three observed patterns are generally true. Prior academic work offers little guidance. Furthermore, many surveys, including recent ones conducted by the International Chamber of Commerce, the International Monetary Fund, and the Bankers' Association for Finance and Trade, are surveys of financial institutions and therefore are based on limited information about transactions financed on cash in advance and open account terms. Fortunately, a survey conducted by FCIB, a trade association of export credit and trade finance specialists, provides some insight. The 2009 International Credit \& Collection Survey asks respondents to report "the top payment method" used in each of a set of countries. The survey is conducted in six parts, each of which covers sales to a particular region of the world, and 50-

100 respondents reply to each part. These respondents are from a diversified set of industries that produce tradeable goods. On each part of the survey, exporters of electronic equipment, chemicals, plastics, and food and kindred products often each comprise about $10 \%$ of respondents. The survey results include the country-level distribution of replies for 44 countries. In these data, cash in advance terms and open account terms are also more commonly used than other terms. 
The average share of respondents reporting cash in advance as the top payment method is $22.2 \%$ across countries, and this figure is $53.9 \%$ for open account, $13.2 \%$ for letters of credit, and $10.7 \%$ for documentary collections.

Exporters that respond to the FCIB survey also use terms that give them less security when selling to markets where contractual enforcement is stronger. This evidence appears in Panel A of Figure 5. The bars reflect the average, computed across countries, of the share of FCIB survey respondents that report open account terms as the top payment method. Within each pair of bars, the unshaded one displays data for countries with relatively strong contractual enforcement and the shaded one for countries with relatively weak contractual enforcement. The four pairs of bars represent sample splits using different proxies for contractual enforcement. For each of the measures, open account terms are more prevalent in countries where the likelihood that contracts are honored is higher.

Panel B presents results of performing similar calculations using the data analyzed elsewhere in this paper. In order to meaningfully compare these data to the results of the FCIB survey, information on 2009 transactions is used to classify each country according to the top payment method. Subsamples of countries are generated using the same criteria used to generate the subsamples that appear in Panel A. The figure reveals that the same pattern in the use of open account emerges; open account terms are used more frequently where contractual enforcement is stronger. ${ }^{13}$

In sum, the FCIB survey results suggest that the first two facts described above generalize. Unfortunately, the data from FCIB or from other sources cannot be easily used to verify how financing terms change as relationships develop.

\section{A Basic Framework}

This section develops a partial-equilibrium model of how the financing terms traders pick are shaped by the institutional environments in which exporters and importers reside.

\subsection{Model Setup}

Environment The model considers the problem of an exporter that markets a set of products within an industry. The revenue obtained from the sale of a particular product in country $j=$ $1, \ldots, N$ is assumed to be a strictly increasing and concave function of the quantity sold in that country, and an increasing function of a demand shifter $\theta$ which may vary across products, i.e.,

$$
R_{j}=R\left(x_{j}, \theta\right), \text { with } \frac{\partial R\left(x_{j}, \theta\right)}{\partial x_{j}}>0, \frac{\partial^{2} R\left(x_{j}, \theta\right)}{\partial\left(x_{j}\right)^{2}} \leq 0, \frac{\partial R\left(x_{j}, \theta\right)}{\partial \theta}>0,
$$

\footnotetext{
${ }^{13}$ It is notable that the measure of the use of open account terms presented in Figure 5 differs from that presented in Figure 3. Figure 5 presents the share of countries in which open account terms are used more than other terms, so this approach effectively equally weights country-level measures. Figure 3 presents value-weighted measures of the use of different terms. The differences in these approaches matter because the exporter makes more extensive use of cash in advance terms in larger markets with weak enforcement of contracts and makes more extensive use of open account terms in larger markets with strong contractual enforcement.
} 
with $R(0, \theta)=R\left(x_{j}, 0\right)=0$. Whether the concavity in the revenue function stems from technology, preferences or market structure is not important for the analysis below. ${ }^{14}$

On the supply side, the exporter faces a marginal cost normalized to 1 for all products regardless of whether it produces and sells them or it acts as an intermediary buying the goods from suppliers and then exporting them. The exporter cannot access foreign consumers directly and needs to contract with an importer in order to make products available to consumers in other markets. Importers only handle one product for the exporter. Shipping goods between any two countries $i$ and $j$ is costly and entails iceberg costs equal to $\tau_{i j}>1$. An additional fixed cost $f_{i j}$ associated with exporting is introduced later on.

Exporting Lags and Trade Finance In order to allow a role for how trade is financed, the model incorporates a delay between the time that goods are produced and the time they are consumed in foreign markets. This captures the fact that it takes a considerable amount of time not only to transport goods but also to fulfill the administrative requirements associated with shipping. To simplify matters, goods are assumed to be produced and shipped at some initial time $t=0$ and to reach foreign countries and be consumed at a later period $t=1$.

If the exporter gets paid at $t=1$, then the exporter acts as if it were lending the exported goods to the importer before the latter can sell these goods to repay the loan. These kinds of financing terms are often referred to as open account terms. Such terms entail financing costs on the part of the exporter, who must fund working capital requirements. In transactions that occur on documentary collection terms, the exporter typically exchanges the goods for payment when the goods reach the importer's location so that such terms can also be mapped to payments occurring at $t=1$. In the empirical part of the paper, these two types of financing terms are combined to create what is referred to as post shipment terms.

If the exporter is paid in advance at $t=0$, then it is as if the importer is lending to the exporter. Transactions that occur on these terms are called cash in advance transactions. They require the importer to fund working capital needs associated with prepayment. After considering cash in advance and post shipment terms, letter of credit terms are introduced in section 3.4.

Contractual Frictions Contractual frictions are captured by assuming that contracting is imperfect due to a problem of limited commitment, as in Hart and Moore (1994) or Thomas and Worrall (1994). In particular, contracts signed at $t=0$ are only enforced with probability $\gamma_{j} \in(0,1)$, where $\gamma_{j}$ is an index of the quality of institutions in country $j$. When a contract is not enforced, parties cannot commit to abide by the initial terms of the contract. For example, when the exporter sells on post shipment terms, the importer is not compelled to honor contractual obligations concerning payment at $t=1$. Analogously, when an importer buys on cash in advance terms, the exporter is

\footnotetext{
${ }^{14}$ The concavity of the revenue function could reflect product differentiation, diminishing returns to scale in producing products, or imperfect competition. This concavity greatly simplifies the exposition of the results. This assumption is also consistent with the negative relationship between transaction prices and sale volumes that is documented in Section D of the Online Appendix.
} 
not compelled to honor contractual obligations concerning the amount or type of goods that are traded. These contractual frictions also affect the financial relationships of traders and their banks, and this issue is discussed in Section 3.3 below.

When financing terms are post shipment terms and the contract is not enforced in the importing country, the importer can threaten to refuse to pay. ${ }^{15}$ This leads to a renegotiation process that reduces the cash flows that the exporter expects to obtain at $t=1$. For simplicity, let the exporter receive in such a case a fraction $\mu_{X}\left(\tau_{i j}\right) \in(0,1)$ of the revenues that would have been generated if the initial contract had been honored. It is assumed that this fraction is a decreasing function of the distance between the two markets, as proxied by transport $\operatorname{costs} \tau_{i j}$. Anecdotally, it is more costly for an exporter to enforce a claim against an importer who is located further away because exporters tend to be less informed about the importer's business practices, and it is more time consuming for the exporter to make use of the dispute resolution mechanisms in the importer's country. In some industries, exporters' main recourse involves shipping goods back to the home market, with those costs naturally rising in distance. ${ }^{16}$

In cash in advance transactions, there is no risk that the importer will not pay because payment occurs before the shipment. However, in such transactions exporters might be tempted to shave the quality or otherwise reduce the value of the goods being shipped. This is captured by assuming that with probability $1-\gamma_{i}$, with $i$ being the exporting country, the initial contract is not enforced, and the exporter is able to avoid a negligibly small effort cost without which the value of the shipment is reduced by a share $1-\delta_{X}$. In such a circumstance, the exporter ships the full value initially agreed at $t=1$ whenever it is privately optimal to do so, which is never the case in a cash in advance transaction but always the case when trade occurs on post shipment terms. ${ }^{17}$ Regulations in the food industry suggest that, for the U.S. exporter from which the data in this study is drawn, $\delta_{X}$ is likely to be close to 1 . In the interest of generality, however, in the static version of the model, the more general case with $\delta_{X} \in(0,1)$ is analyzed.

The initial contract signed by the exporter and the importer specifies a volume of trade $x_{j}$ and a payment $P_{t, i j}$ from the importer to the exporter that occurs either at $t=0$ or at $t=1$. The analysis of endogenous financing costs below is significantly simplified when the exporter makes a take-it-or-leave-it offer to the importer, so this assumption is made throughout the analysis. As explained in Section A of the Online Appendix, the model's predictions are not greatly changed under different assumptions about the ex-ante bargaining power held by each party. Finally, it is

\footnotetext{
${ }^{15}$ Although contracts governing payments related to trade can specify a dispute resolution process and legal system that should be used in case of a disagreement, enforcing awards ultimately requires the support of the law in the country where the party that must make amends has assets. See Foley, Johnson, and Lane (2010) for additional information about resolution dispute mechanisms.

${ }^{16}$ Another way in which distance could affect the profitability of a transaction is by increasing the time lag between the shipment and receipt of goods. This obviously increases the working capital needs associated with that transaction and also possibly increases the probability of contract default. Section B of the Online Appendix briefly discusses this alternative channel and shows it does not deliver clear comparative statics for the effect of distance on the trade finance mode.

${ }^{17}$ This assumes that the exporter learns whether or not the contract is enforced in its country before it ships the goods to the importer.
} 
assumed that the importer has no wealth and is protected by limited liability, in the sense that the amount paid by the importer can not exceed the market value of the purchased goods.

\subsection{Trade Finance Choice with Exogenous Financing Costs}

To build intuition, it is useful to begin by studying the choice between transactions on post shipment terms and cash in advance terms while taking the costs of financing working capital requirements as exogenous, although these are endogenized later. In a cash in advance transaction, the importer

in country $j$ pays the exporter in $i$ at $t=0$. Denote that payment by $P_{0, i j}^{C I A}$. If $r_{j}$ denotes the financing cost faced by the importer, the participation constraint of this agent is

$$
\left(1+r_{j}\right) P_{0, i j}^{C I A} \leq\left(\gamma_{i}+\left(1-\gamma_{i}\right) \delta_{X}\right) R\left(x_{j}, \theta\right)
$$

where the right-hand-side of the inequality equals the expected revenues that the importer anticipates obtaining at $t=1$. The expression reflects that with probability $1-\gamma_{i}$ the exporter is not required to abide by the initial contract and optimally shaves the value of the shipment by a share $1-\delta_{X}$. Given that at $t=0$ the exporter makes a take-it-or-leave-it offer to the importer, $P_{0, i j}^{C I A}$ is set so that the above inequality holds with equality and the exporter chooses the level of exports $x_{j}$ to be included in the initial contract that solves

$$
\pi_{i j}^{C I A}=\max _{x_{j}}\left\{\frac{\left(\gamma_{i}+\left(1-\gamma_{i}\right) \delta_{X}\right)}{1+r_{j}} R\left(x_{j}, \theta\right)-\tau_{i j} x_{j}\right\}
$$

Next, consider a transaction that occurs on post shipment terms. When making a take-it-orleave-it offer, the exporter demands that the importer pay all revenue obtained in country $j$ at $t=1$. However, the contract is only honored with probability $\gamma_{j}$, and when it is not, the exporter only recoups a share $\mu_{X}\left(\tau_{i j}\right)$ of sale revenues. This implies that the exporter does not anticipate a $t=1$ payment larger than

$$
P_{1, i j}^{P S T}=\left(\gamma_{j}+\left(1-\gamma_{j}\right) \mu_{X}\left(\tau_{i j}\right)\right) R\left(x_{j}, \theta\right)
$$

In order to generate that payment at $t=1$, the exporter finances its working capital need at a cost given by $r_{i}$. The exporter thus chooses the level of exports $x_{j}$ to solve

$$
\pi_{i j}^{P S T}=\max _{x_{j}}\left\{\frac{\left(\gamma_{j}+\left(1-\gamma_{j}\right) \mu_{X}\left(\tau_{i j}\right)\right)}{1+r_{i}} R\left(x_{j}, \theta\right)-\tau_{i j} x_{j}\right\} .
$$

When transacting on post shipment terms, the exporter has no incentive to shave the quality of the goods being exported because doing so would only reduce its payoff.

Applying the envelope theorem to expressions (3) and (4) reveals that, for given financing costs $r_{i}$ and $r_{j}$, institutional parameters $\gamma_{i}$ and $\gamma_{j}$, and transport $\operatorname{costs} \tau_{i j}$, the exporter prefers the use 
of cash in advance terms over post shipment terms if and only if

$$
\frac{\gamma_{i}+\left(1-\gamma_{i}\right) \delta_{X}}{1+r_{j}}>\frac{\gamma_{j}+\left(1-\gamma_{j}\right) \mu_{X}\left(\tau_{i j}\right)}{1+r_{i}} .
$$

The choice is governed by the relative magnitude of the contractual frictions and exogenous financing costs associated with each financing mode. The likelihood that a transaction occurs on cash in advance terms as opposed to post shipment terms is decreasing in the strength of contractual enforcement in the importing country $\left(\gamma_{j}\right)$ and is increasing in the distance between the importing and exporting countries $\left(\tau_{i j}\right)$. Both a decrease in $\gamma_{j}$ and an increase in $\tau_{i j}$ are associated with larger frictions stemming from limited commitment on the part of the importer. Furthermore, the negative effect of weak contractual enforcement in the importer's country on the expected relative profitability of post shipment terms is alleviated by the proximity of markets. The relative attractiveness of cash in advance terms is also enhanced by a strong contractual environment in the exporting country (high $\gamma_{i}$ ), as well as by high financing costs in the exporting country or low financing costs in the importing country.

The theoretical result regarding the effect of the importer country's institutional quality provides a simple explanation for the second stylized fact described in Section 2. Buyers in countries with weaker contracting are tempted to default with higher probability, and, for given financing costs, this induces the exporter to make more extensive use of cash in advance terms. As intuitive as the result might appear, it carries an important qualification when financing costs are endogenized.

\subsection{Trade Finance Choice with Endogenous Financing Costs}

As explained above, cash in advance terms require importers to fund working capital needs and post shipment terms require the exporter to fund working capital needs. If funding costs are higher in weak institutional environments, cash in advance terms may not be as desirable for transactions involving importers in such environments. It is therefore informative to endogenize financing costs.

In order to satisfy the up-front payment $P_{0, i j}^{C I A}$ in a transaction that occurs on cash in advance terms, assume that the importer approaches a local bank to borrow the value of this payment. Assume also that the banking sector is competitive, and the cost of funds is equal to $1+\rho_{j}$. The

level of $\rho_{j}$ can be interpreted as an inverse measure of the technological efficiency of the banking sector in the importing country. Banks are not, however, willing to lend at an interest rate equal to $\rho_{j}$ because of the same limited commitment constraints that induce exporters to favor cash in advance over post shipment terms. The importer cannot credibly pledge all the revenue obtained at $t=1$ to a local bank, and this in turn implies that the exporter is not able to extract all surplus from the importer even when making a take-it-or-leave-it offer. More formally, assume that when the $t=0$ financial contract between the bank and the importer is not enforced, the importer defaults, or threatens to default, and the bank can only recoup a payment that equals a fraction $\mu_{B}$ of the revenues generated at $t=1$. The importer's bank thus anticipates that the maximum expected repayment that it can obtain from the importer is equal to a fraction $\gamma_{j}+\left(1-\gamma_{j}\right) \mu_{B}$ 
of the expected revenues in a transaction that occurs on cash in advance terms. Recall that these revenues are given by $\left(\gamma_{i}+\left(1-\gamma_{i}\right) \delta_{X}\right) R\left(x_{j}, \theta\right)$. In sum, the participation constraint of the local bank imposes the following financial constraint on the importer

$$
\left(1+\rho_{j}\right) P_{0}^{C I A} \leq\left(\gamma_{j}+\left(1-\gamma_{j}\right) \mu_{B}\right)\left(\gamma_{i}+\left(1-\gamma_{i}\right) \delta_{X}\right) R\left(x_{j}, \theta\right)
$$

which in light of equation (2) delivers

$$
1+r_{j}=\frac{1+\rho_{j}}{\gamma_{j}+\left(1-\gamma_{j}\right) \mu_{B}}
$$

Quite intuitively, the importer's financing costs are higher in countries with weaker institutions (lower $\gamma_{j}$ ) and with less efficient banking sectors (higher $\rho_{j}$ ). Plugging this value into (3) the profitability of a cash in Advance transaction with endogenous financing costs is given by

$$
\pi_{i j}^{C I A}=\max _{x_{j}}\left\{\frac{\left(\gamma_{i}+\left(1-\gamma_{i}\right) \delta_{X}\right)\left(\gamma_{j}+\left(1-\gamma_{j}\right) \mu_{B}\right)}{1+\rho_{j}} R\left(x_{j}, \theta\right)-\tau_{i j} x_{j}\right\} .
$$

Next, consider the financing costs faced by exporters when transactions occur on post shipment terms. Remember that the exporter anticipates obtaining expected revenues equal to $\gamma_{j} R\left(x_{j}\right)+$ $\left(1-\gamma_{j}\right) \mu_{X}\left(\tau_{i j}\right) R\left(x_{j}\right)$ at $t=0$. However, the exporter can only pledge a fraction of these revenues to its local bank because financial contracts are only enforced with probability $\gamma_{i}$, and when they are not, the bank can at most obtain a fraction $\mu_{B}$ of these revenues. The level of $x_{j}$ chosen by the exporter must hence satisfy the inequality

$$
\left(1+\rho_{i}\right) \tau_{i j} x_{j} \leq\left(\gamma_{i}+\left(1-\gamma_{i}\right) \mu_{B}\right)\left(\gamma_{j}+\left(1-\gamma_{j}\right) \mu_{X}\left(\tau_{i j}\right)\right) R\left(x_{j}, \theta\right)
$$

where $\rho_{i}$ is the cost of funds in the exporting country. One can show that for sufficiently large $\gamma_{i}$ or $\mu_{B}$, this inequality does not bind, and $r_{i}=\rho_{i}$ because the exporter is able to pledge a sufficiently large ex-post payoff to the bank. The analysis focuses on this case for three reasons: first, it simplifies the exposition of the main results; second, the exporter in the data is based in the U.S. where the enforcement of contracts is particularly strong; and third, the emphasis in the paper is on the effects of variation in the importer's financing costs on the choice of financing terms.

Plugging $r_{i}=\rho_{i}$ into (4) and using the envelope theorem reveals that, with endogenous financing costs, the exporter prefers cash in advance terms to post shipment terms if and only if

$$
\gamma_{i}+\left(1-\gamma_{i}\right) \delta_{X}>\frac{1+\rho_{j}}{1+\rho_{i}} \frac{\gamma_{j}+\left(1-\gamma_{j}\right) \mu_{X}\left(\tau_{i j}\right)}{\gamma_{j}+\left(1-\gamma_{j}\right) \mu_{B}}
$$

Differentiation delivers:

Proposition 1 With endogenous financing costs, the likelihood that a transaction occurs on cash in advance terms as opposed to post shipment terms is decreasing in the institutional quality of 
the importing country $\left(\gamma_{j}\right)$ if and only if $\mu_{X}\left(\tau_{i j}\right)<\mu_{B}$, that is if and only if local banks in the importing country are more effective than exporters in pursuing financial claims against importers.

Proposition 1 indicates that the patterns unveiled in Section 2.2 can be explained by the model but only when local banks are more effective in pursuing claims in the case of default, that is when $\mu_{B}>\mu_{X}\left(\tau_{i j}\right)$. This seems a natural assumption to make given that a local bank is likely to be familiar with an importer's business and is more able to use local dispute resolution mechanisms because it is close by and familiar with them. Still, there may be situations in which exporters are better able to pursue these claims than local banks. This could occur, for instance, in situations in which the exporter ships highly specialized machines or inputs so that it is easier for that exporter than for a local bank to redeploy those machines in case of default. Burkart and Ellingsen (2004) develop this idea in a model of trade credit. ${ }^{18}$

In sum, the modelling of endogenous financing costs leads to an important qualification of the effect of the institutional quality of the importer's country on the mode of financing. However, the remaining comparative statics discussed in the case of exogenous financing costs hold regardless, implying:

Proposition 2 With endogenous financing costs, the likelihood that a transaction occurs on cash in advance terms as opposed to post shipment terms is increasing in the distance between the importing and exporting countries $\left(\tau_{i j}\right)$. Furthermore, the negative effect of weak importer institutions on the expected relative profitability of transactions that occur on post shipment terms is alleviated by proximity between markets.

\subsection{Letters of Credit}

Letters of credit can be incorporated into the model by assuming that they accomplish two objectives. First, a letter of credit ensures that the exporter only receives payment whenever its shipment is in accordance with the initial contract. Hence, a letter of credit eliminates, or at least diminishes, the possibility that the exporter reduces the value of the shipped goods. Second, a letter of credit substitutes the trustworthiness of the importer's bank for that of the importer, and it is assumed that the exporter necessarily gets paid if it meets its contractual obligations. However, in a letter of credit transaction, the importer must make a payment to the importer's bank. Following the modelling choices above, the importer cannot commit not to renege on its promised payment, and if it fails to meet its obligation, the bank can collect a share of the importer's revenues, $\mu_{B}>\mu_{X}\left(\tau_{i j}\right)$. Furthermore, letters of credit are associated with a processing cost incurred by the importer's bank, and this cost is modelled as an increase in the cost of funding by a factor $\psi_{j}>1$. As indicated

\footnotetext{
${ }^{18}$ It has been assumed that the costs of default, as parameterized by $\mu_{X}\left(\tau_{i j}\right)$ and $\mu_{B}$ are independent of the importing country's institutional quality $\gamma_{j}$. A natural extension would be to consider environments in which both $\mu_{X}\left(\tau_{i j}\right)$ and $\mu_{B}$ increase in $\gamma_{j}$. Straightforward differentiation of (9) indicates that as long as $\mu_{X}\left(\tau_{i j}\right)$ is more responsive to $\gamma_{j}$ than $\mu_{B}$ is (a plausible assumption), it continues to be the case that the likelihood of a transaction occuring on cash in advance terms is decreasing in $\gamma_{j}$.
} 
above, the banking sector in the importer's country is assumed to be competitive and to break even.

Following the same steps as above reveals that the profits for the exporter in a letter of credit transaction are given by:

$$
\pi_{i j}^{L C}=\max _{x_{j}}\left\{\frac{\left(\gamma_{j}+\left(1-\gamma_{j}\right) \mu_{B}\right)}{\psi_{j}\left(1+\rho_{j}\right)} R\left(x_{j}, \theta\right)-\tau_{i j} x_{j}\right\} .
$$

Comparing this with expressions for $\pi_{i j}^{C I A}$ and $\pi_{i j}^{P S T}$ above reveals that the exporter prefers using a letter of credit as opposed to cash in advance terms whenever

$$
\frac{1}{\psi_{j}}>\gamma_{i}+\left(1-\gamma_{i}\right) \delta_{X}
$$

Notice that this inequality cannot possibly hold if $\gamma_{i}$ or $\delta_{X}$ are close enough to 1 . Furthermore, the exporters prefer a letter of credit over post shipment terms whenever

$$
\frac{1}{\psi_{j}}>\frac{1+\rho_{j}}{1+\rho_{i}} \frac{\gamma_{j}+\left(1-\gamma_{j}\right) \mu_{X}\left(\tau_{i j}\right)}{\gamma_{j}+\left(1-\gamma_{j}\right) \mu_{B}}
$$

where the right-hand-side is identical to that of inequality (9). From these expressions, the following conclusions follow:

Proposition 3 Letters of credit are unlikely to be optimal whenever the exporter's scope for misbehavior is limited (in the sense that either $\gamma_{i}$ or $\delta_{X}$ are close to 1 ). The level of contractual enforcement of the importing country, as captured by $\gamma_{j}$, is irrelevant for the choice between a letter of credit and cash in advance terms. Conversely, the choice between a letter of credit and post shipment terms is shaped by the institutional quality of the importing country and by distance in a manner identical to the choice between cash in advance and post shipment terms.

The first statement in Proposition 3 helps rationalize the fact that letters of credit are not prevalent in the data used in this paper. The model suggests that this is because the exporter is located in the U.S. where contractual enforcement is strong and, perhaps more importantly, because the type of goods that it sells are not prone to quality manipulation given the tight regulations governing trade in food. Intuitively, in such cases, the only benefit of a letter of credit is to substitute the trustworthiness of the importer's bank for that of the importer, but the same can be achieved at lower cost with a cash in advance contract. With regards to the second statement in Proposition 3, it should be emphasized that although inequality (10) is independent of $\gamma_{j}$, to the extent that the fees $\psi_{j}$ charged on letters of credit are affected by the quality of institutions in the importing country, these institutional variables may in fact significantly affect the choice between a letter of credit and cash in advance terms. Finally, the last statement suggests that in empirical applications where the key variation is in importer characteristics, the use of cash in advance and letters of credit should be similar. 


\section{Relationship Dynamics and the Crisis}

This section introduces an extension of the framework that sheds light on the effect of relationships on the choice of financing terms. This extension is also useful in generating predictions about the effects of the recent economic crisis. For simplicity, this section rules out the possibility of misbehavior on the part of the exporter by assuming $\delta_{X}=1$, so that letters of credit are a dominated financing mode. This seems reasonable for the empirical setting considered, given the nature of the traded goods and the fact that letters of credit are rarely used in the data. The analysis also assumes, as before, that the exporter is not credit constrained and thus $r_{i}=\rho_{i}$. Furthermore, given $\delta_{X}=1$, for post shipment terms not to be a dominated option, it is necessary to assume $\rho_{j}>\rho_{i}$, or that the exporter's banking system is more technologically efficient than the importer's. There is substantial customer turnover in the data, and to generate this a fixed cost $f_{i j}$ associated with exporting from country $i$ to country $j$ is introduced. If the exporter incurs this cost, this modification simply amounts to adding a term $-f_{i j}$ in the profit functions derived above and has no bearing on the results in Propositions 1 though 3.

\subsection{Dynamics}

In the previous setup in which the exporter and the importer transact only once, it is optimal for importers to deviate from their contractual obligations if contracts are not enforced. Suppose instead that these agents interact on a repeated basis, and for simplicity, assume that the game played between these agents is or is perceived to be infinitely repeated. Assume also that importers come in two types: they are either always patient and discount the future at a very low rate, or they are stochastically myopic in which case, with probability $\lambda$, they care only about current payoffs and, with the complementary probability $1-\lambda$, they are patient. Shocks to importers' discount factors can be interpreted as liquidity shocks. When an importer is hit by a liquidity shock it threatens to default when given the chance, which occurs with probability $1-\gamma_{j}$. Conversely, the exporter and the importer's bank can use the threat of discontinuing the relationship to get patient importers to meet their contractual obligations. Provided that the discount rate of patient importers is sufficiently low, the folk theorem implies that an equilibrium exists in which patient importers never threaten to default. It is assumed that this is the case, and thus patient agents are always trustworthy. ${ }^{19}$

While defaults are publicly observed, whether an agent is always patient or stochastically myopic is private information to that agent. The exporter and the importer's bank can only form beliefs on the type of the particular importer they are dealing with. ${ }^{20}$ How are these beliefs formed? First, it is common knowledge that, at any point in time, a fraction $1-\chi$ of the population of importers is stochastically myopic. Hence, a new importer is perceived to be always patient with probability $\chi$.

\footnotetext{
${ }^{19}$ This requires that the importer obtains some positive payoff when it chooses to honor the contract. Still, for a discount factor close enough to 1 , this required payoff can be made arbitrarily close to 0 . This limiting case is considered for simplicity.

${ }^{20}$ The analysis rules out the possibility of the exporter offering a menu of contracts to screen the importer's type.
} 
In repeated relationships, however, the probability assigned to the importer being always patient evolves over time and increases with a history of no defaults. Denoting by $\hat{\chi}(T)$ the particular posterior probability assigned to the importer being always patient in a relationship of length $T$ and using Bayes' rule reveals that

$$
\widehat{\chi}(T)=\frac{\chi}{\chi+(1-\chi)(1-\lambda+\lambda \gamma)^{T}}>\chi
$$

when there have been no defaults up to length $T$, and $\widehat{\chi}(T)=0$ otherwise. Whenever an importer fails to meet its contractual obligations, the exporter and the importer's bank optimally choose to stop trading with the importer and begin to trade with a new importer, who is perceived to be patient with probability $\chi$. Note that, as long as there are no defaults, $\widehat{\chi}(T)$ is increasing in $T$ and thus as relationships evolve with no defaults, the exporter and the importer's bank assign a higher and higher probability to the importer being always patient.

How does this reputation building process affect the profitability of different trade financing arrangements? Consider first the case of post shipment transactions. In a relationship of length $T$ with no prior defaults, profits of this option are given by

$\pi_{i j}^{P S T}(T)=\max _{x_{j}}\left\{\frac{\left[\gamma_{j}+\left(1-\gamma_{j}\right)\left(\widehat{\chi}(T)+(1-\widehat{\chi}(T))\left(1-\lambda+\lambda \mu_{X}\left(\tau_{i j}\right)\right)\right)\right] R\left(x_{j}, \theta\right)}{1+\rho_{i}}-\tau_{i j} x_{j}-f_{i j}\right\}$,

where the term in square brackets captures the probability with which the exporter believes that it will be paid the initially contracted amount at $t=T$. This probability is increasing in the length of an existing relationship, as the trust in the importer grows over time in the absence of defaults.

Consider next the case of cash in advance transactions, in which there exists the possibility of the importer defaulting on its bank, though again this probability is perceived to decrease with a history of no prior defaults. Given public information on past defaults, the exporter and the importer's bank terminate and reinitiate relationships in a similar manner. As a result, the length of the exporter-importer relationship coincides with the length of the importer-bank relationship, and the profits associated with a cash in advance transaction in a relationship of length $T$ with no prior defaults are given by:

$$
\pi_{i j}^{C I A}(T)=\max _{x_{j}}\left\{\frac{\left(\gamma_{j}+\left(1-\gamma_{j}\right)\left(\widehat{\chi}(T)+(1-\hat{\chi}(T))\left(1-\lambda+\lambda \mu_{B}\right)\right)\right) R\left(x_{j}, \theta\right)}{1+\rho_{j}}-\tau_{i j} x_{j}-f_{i j}\right\} .
$$

Comparing equations (11) and (12), reveals that:

Proposition 4 Provided that $\mu_{X}\left(\tau_{i j}\right)<\mu_{B}$, the likelihood that a transaction with a particular importer occurs on post shipment terms increases with the number of past interactions between the exporter and that particular importer. Furthermore, in importing countries where contractual enforcement is close to perfect, that is when $\gamma_{j} \rightarrow 1$, the effect of past interactions on the relative profitability of transactions that occur on post shipment terms vanishes. 
Intuitively, the reputation-building process that occurs through repeated interaction substitutes for strong institutions, so the result bears a clear analogy to that in Proposition 1. A corollary of Proposition 4 is that, other things equal, the likelihood that a transaction occurs on post shipment terms is lower for transactions involving new customers relative to transactions involving repeat customers. This prediction is consistent with the patterns documented in Table 2. It also follows from (11) and (12) that, whenever $\mu_{X}\left(\tau_{i j}\right)<\mu_{B}$, the likelihood that a transaction with a particular importer occurs on post shipment terms decreases with the probability of a liquidity shock $\lambda$ (see the next section for more on this)..$^{21}$

The solid curves presented in Figure 6 provide a graphical illustration of the effect of past interactions on the choice of financing mode. This graph is constructed for the interesting case in which $\gamma_{j}$ is such that $\pi_{i j}^{P S T}<\pi_{i j}^{C I A}$ for $T=0$, and hence, there exists a unique relationship length $T^{*}$, such that cash in advance terms are optimal for $T<T^{*}$, while post shipment terms are optimal for $T>T^{*}$. If instead $\pi_{i j}^{P S T}>\pi_{i j}^{C I A}$ for $T=0$, then cash in advance would never be optimal. ${ }^{22}$

\subsection{A Crisis}

The dynamic extension of the model is also helpful for understanding patterns in customer turnover and the effects of the recent crisis. The recent crisis can be interpreted as a fall in demand, that is a fall in $\theta$ in the model, or as an increase in expected default stemming from an increase in the probability of a liquidity shock $\lambda$ faced by stochastically myopic importers. Obviously, the approach here is very much reduced form: the fall in demand and increase in defaults would interact with each other in a more detailed model.

Figure 6 illustrates the effects of a fall in $\theta$ on the prevalence of the use of cash in advance terms and post shipment terms. Equations (11) and (12) indicate that the fall in $\theta$ reduces the profits of transactions that occur on both types of terms and increases the probability that an export relationship is terminated because the fixed costs of exporting cannot be covered. In the figure, the dashed lines indicate negative profits for values of $T$ below $\underline{T}$. This implies that importers that traded on cash in advance terms before the demand shift are more likely to stop trading with the exporter than importers that traded on post shipment terms. In other words, the extensive margin response to a fall in demand should, other things equal, be larger for cash in advance transactions. The fall in $\theta$ also reduces the intensive margin or volume of export sales of surviving relationships. Without further restrictions on the function $R\left(x_{j}, \theta\right)$, it is unclear if decreases on the intensive

\footnotetext{
${ }^{21}$ In our model, the probability of defaults is affected by $\chi, \lambda$ and $\gamma_{j}$. Increases in $\chi$ and reductions in $\lambda$ always affect the relative profitability of post shipment terms and cash in advance terms in the same direction as an increase in $\gamma_{j}$ does. When the probability of contractual breaches increases, regardless of the reason, the relative profitability of post shipment terms increases (provided that $\mu_{B}>\mu_{X}\left(\tau_{i j}\right)$ whenever financing costs are endogenous).

${ }^{22}$ This analysis makes some assumptions that are noteworthy. First, this section has assumed that $\delta_{X}=1$, implying that the exporter does not deliver substandard goods. If $\delta_{X}$ were sufficiently lower than 1 , repeated interaction could be associated with learning not only about the importer's type but also about the exporter's type, and the theoretical results could be quite different. Second, the analysis makes the assumption that the exporter and the importer's bank update their beliefs on the importer's type in a symmetric fashion. The trade credit literature has argued that, in some cases, sellers might have a comparative advantage relative to financial intermediaries in learning about the trustworthiness of their buyers. This possibility is explored in Section C of the Online Appendix.
} 
margin are larger for importers that were transacting on cash in advance terms or post shipment terms. In fact, for the often used case of isoelastic revenue functions, the effect is proportionate for all firms, as illustrated in Figure 6.

An increase in the probability that stochastically myopic importers face liquidity shocks generates richer effects which are depicted in Figure 7. First, note from equations (11) and (12) that the increase in $\lambda$ reduces the profitability of transactions that occur on both cash in advance and post shipment terms. ${ }^{23}$ As in the case of a fall in $\theta$, the increase in $\lambda$ implies that trade with importers that were transacting on cash in advance terms before the shock is more likely to become unprofitable than trade with importers that were transacting on post shipment terms. Differentiation demonstrates a second effect; for a given length of the relationship $T$, the profitability of transactions that occur on post shipment terms is more severely affected than that of transactions that occur on cash in advance terms. Intuitively, the increase in $\lambda$ has a similar effect as a decrease in the strength of contractual enforcement in the importer's country in the static model. As a consequence of this result, the exporter becomes more likely to use cash in advance terms when transacting with new customers during the crisis than before it. It is also important to note that an increase in $\lambda$ reduces profits by lower amounts for more established trading relationships, or relationships where $T$ is higher. The probability the exporter assigns to the importer being stochastically myopic is very low in long-term relationships without prior defaults. An implication of this result is that importers that transacted with the exporter on post shipment terms prior to the crisis decrease their purchases disproportionately less when the crisis hits.

\section{$5 \quad$ Econometric Evidence}

The model has several testable implications. In line with the model, documentary collection and open account transactions are aggregated into a single category called post shipment terms. Propositions 1-3 predict that cash in advance terms and letter of credit terms are preferred to post shipment terms when contractual enforcement is weak in the importer's country and that contractual enforcement of the importer's country does not affect the choice between cash in advance and letter of credit terms. The patterns displayed in Figure 3 which is described above are roughly consistent with these ideas, but they are tested more rigorously using the specifications presented in Table 4 below. Propositions 2 and 3 point out that cash in advance terms and letters of credit terms are preferred to post shipment terms when there is more distance between the exporter and the importer and that the impact on contract choice of weak contractual enforcement is alleviated by proximity. Figure 8 below presents tests of these predictions.

The model also has implications for how the development of trading relationships affects the terms used. Proposition 4 predicts that transactions are more likely to occur on post shipment terms as a relationship develops and that the impact of relationships is largest when contractual

\footnotetext{
${ }^{23}$ In computing the effect of the increase in $\lambda$ on the profits in equations (11) and (12), one should hold $\widehat{\chi}(T)$ fixed because that belief is shaped by past default probabilities, not by current or future ones. The new default probability $\lambda^{\prime}>\lambda$ affects how future beliefs $\widehat{\chi}\left(T^{\prime}\right)$ for $T^{\prime}>T$ are formed.
} 
enforcement is weak. Figure 4 provides suggestive evidence of the impact of the development of a trading relationship, and tests in Table 5 below analyze the effects of past interactions more carefully. Finally, Section 4.2 also formulates predictions about the effects of the recent economic crisis. Empirical facts related to these predictions appear in Tables 6, 7, and 8. Before turning to the tests, the text describes other data items that are used.

\subsection{Other Data Items}

Additional data items are based on the exporter's data and a variety of other sources. The transaction-level data from the exporter can be used to infer attributes of trading relationships between the exporter and importers. It is possible to compute several measures of the extent to which the exporter has gained experience trading with a customer. One such measure is the sum of the value of past sales that the exporter has made to a particular customer. Another is the count of the number of past transactions the exporter has engaged in with a particular customer. Each of these provides a proxy for the extent to which the exporter has been able to collect information about a customer. ${ }^{24}$

Measures of the strength of the enforcement of contracts are merged into the transaction data. In addition to the four proxies described above, the analysis below considers four other proxies as well. These are confidence in legal system, duration of legal procedure, private credit, and stock market capitalization. ${ }^{25}$ The analysis also makes use of two other country measures. Distance measures the number of miles from the capital of each country to Washington, DC, and GDP per capita is measured in nominal US dollars and comes from the Economist Intelligence Unit. Several of the areas that the exporter serves are protectorates of other countries, and for these, the analysis assigns the institutional features of the independent state that governs the nonindependent entity. For example, American Samoa is assigned the institutions of the U.S. because it is a U.S. territory. Table 3 displays descriptive statistics for the tests described below.

\subsection{The Enforcement of Contracts, Distance, and Financing Terms}

The extent to which contractual obligations are likely to be enforced features prominently in the theory developed above. Table 4 presents results of some coefficients generated by multinomial logit specifications that analyze how proxies for the enforcement of contracts affect the type of financing terms that are chosen. These specifications consider three groupings of financing terms:

\footnotetext{
${ }^{24}$ However, these measures are subject to the concern that the sample begins in 1996 so it is not possible to determine the extent of trade prior to this date. Tests below therefore use 1996 data to compute proxies for trading relationships but then drop observations from 1996 to test for the effects of relationships. The analysis below also considers if new customers appearing in the data after 1996 receive distinctive financing terms.

${ }^{25}$ Confidence in legal system is drawn from a World Bank Survey of managers on the degree to which they believe the system will uphold contracts and property rights in a business dispute, and higher values imply greater confidence. Duration of legal procedure is taken from Djankov, La Porta Lopez-de-Silanes, and Shleifer (2003), and it measures the total estimated duration in calendar days to pursue a claim on a bounced check. Two outcome based measures of the development of institutions that protect financial claimants are drawn from the World Bank's Financial Structure database. Private Credit is the ratio of private credit by deposit money banks and other financial institutions to GDP, and Stock Market Capitalization is the value of listed shares to GDP.
} 
cash in advance terms, letter of credit terms, and post shipment terms. Measures of the strength of contract enforcement are the independent variables of interest, and eight different measures are considered, one at a time. Each specification includes a fixed effect for each year and each of the product types depicted in Figure 2 and controls for the log of the distance between Washington, DC and the capital city of the destination country and the log of GDP per capita in the destination country to ensure that measures of the strength of contract enforcement do not pick up the effects of distance or country income. Standard errors are clustered at the country level.

The first column reports coefficient estimates of the effects of the strength of contractual enforcement on the relative choice of cash in advance and post shipment terms. The negative and significant coefficient on the common law dummy in the first column implies that cash in advance terms are used less in countries with a common law legal origin than post shipment terms. The second column reports coefficient estimates for the choice between letter of credit terms and post shipment terms. The negative and significant coefficient in this column implies that letters of credit are also less frequently used in common law countries than post shipment terms. The third column contains coefficient estimates for the choice between cash in advance terms and letter of credit terms. Consistent with the predictions of the model, common law legal origin does not have a significant effect on the relative use of these financing terms. The marginal effects of selling to a common law country implied by the results are large. The results predict that moving from a common law country to a civil law country increases the probability that cash in advance terms are used from $4.0 \%$ to $31.7 \%$, increases the probability that letter of credit terms are used from $0.4 \%$ to $4.1 \%$, and decreases the probability that post shipment terms are used from $95.6 \%$ to $64.2 \%$.

Results are largely consistent for other measures of the strength of enforcement of contractual obligations. If contracts are more viable, payment delays are less problematic, contracts are more enforceable, or there is greater confidence in the legal system, transactions are less likely to make use of cash in advance relative to post shipment terms and less likely to make use of letter of credit relative to post shipment terms. Similar choices are associated with outcome based measures of the enforcement of contractual obligations, namely the depth of private credit markets and stock markets, although the private credit variable is not significant in explaining the choice between letter of credit and post shipment terms. When the duration of legal procedures associated with pursuing a claim on a bounced check is longer, cash in advance terms appear to be preferred to post shipment terms and letter of credit terms appear to be preferred to post shipment terms, but this measure is only significant in explaining the second of these relative choices. Only one of the measures of the strength of contractual enforcement has a significant coefficient in explaining the choice between cash in advance terms and letter of credit terms. Private credit is negative and significant, suggesting that cash in advance terms are more frequently used than letter of credit terms when private credit markets are shallow, perhaps reflecting that fees on letters of credit are disproportionately higher in those environments. These findings broadly support the predictions about the effects of the institutional quality of the importer's country that are put forth in Propositions 1-3. 
The results in Table 4 appear to be robust in tests that explore whether measures of contractual enforcement proxy for other factors. First, the model suggests a role for the technological efficiency of the banking sector in the importer's country, which is denoted by $\rho_{j}$ and captures factors affecting interest rates that are not related to contractual enforcement. Results are little changed by including interbank interest rates or central bank discount rates in the specifications. Second, measures of the strength of contractual enforcement could be correlated with the amount of trade that takes place between the exporter and importer or with expected shipment times. The measure of distance that is included in the specifications is highly correlated with expected shipment times, but it is possible to control for expected shipment time directly using data provided by the exporter. Including controls for the value of sales, volume of sales, the sum of past sales values from the exporter to the importer, and expected shipping times does not materially affect the findings about the role of contractual enforcement. Third, the strength of contractual enforcement might be associated with the concentration of importers, and buyers might have more bargaining power in concentrated markets. Conditioning on the Herfindahl index of sales to each country in each year does not materially affect the results. ${ }^{26}$

Propositions 2 and 3 have implications for the effects of distance and the interaction of distance and measures of the strength of contractual enforcement. The specifications used to generate the results presented in Table 4 include the log of distance, and the coefficient on this variable is positive and significant in explaining the choice between cash in advance and post shipment terms in 7 of 8 specifications, and it is positive and significant in explaining the choice between letter of credit and post shipment terms in 6 of 8 specifications. Thus, longer distances are associated with greater use of cash in advance and letter of credit terms relative to post shipment terms, consistent with the predictions. $^{27}$

These propositions also have implications for analysis of the interaction of distance and the strength of contractual enforcement, but this analysis raises the issue that interaction terms can be difficult to interpret in multinomial logit models, as discussed in Ai and Norton (2003). Greene (2010) suggests using graphical presentations to display results. Figure 8 illustrates estimates generated from running multinomial specifications that are identical to those presented in Table 4 except distance is measured using a dummy that is equal to one for transactions with customers further from the U.S. than the mean export, and the specifications each include interactions of this distance measure with one of the eight measures of contractual enforcement.

Each panel displays the estimated likelihood that a transaction occurs on post shipment terms. The clear bars in Panel A and the dashed lines in Panels B-H show estimates for nearby customers

\footnotetext{
${ }^{26}$ Tables that display these robustness tests appear in the Online Appendix. One sample selection issue is worth noting. The data only include transactions that actually occur. According to the theory, decreases in the institutional quality of the importer's country reduce the profitability of all types of transactions, so transactions in countries with weaker contractual enforcement are less likely to occur. If, as suggested by the results, $\mu_{B}>\mu_{X}\left(\tau_{i j}\right)$, unobserved transactions would be more likely to occur on cash in advance and letter of credit terms. Therefore, the effect of contractual enforcement on the use of these terms relative to post shipment terms would be likely to be larger than indicated in the first two columns of Table 4 if one does not condition on transactions actually occuring.

${ }^{27}$ Estimates of distance coefficients from the analysis in Table 4 appear in the Online Appendix.
} 
which are located in countries with differing levels of contractual enforcement, and the shaded bars and solid lines show estimates for more remote customers. In each panel, increases in the strength of contractual enforcement are associated with larger increases in the likelihood of using post shipment terms for remote customers than for nearby customers. For example, the propensity to use post shipment terms is 61.0 percentage points higher for customers located in common as opposed to civil law countries when these countries are remote but only 13.4 percentage points higher when these countries are nearby. For more remote customers, post shipment terms are more frequently used when the destination country has a common law legal origin, higher contract viability, fewer problems related to payment delays, more enforceable contracts, greater confidence in the legal system, shorter duration of legal procedures, deeper private credit markets, and larger stock markets.

The graphs in each panel also include error bars that illustrate $95 \%$ confidence intervals. These indicate that it is difficult to distinguish between the likelihood of using post shipment terms for nearby customers across countries with different levels of contractual enforcement. The use of post shipment terms appears to increase with the level of contractual enforcement for more remote customers, beginning at values below those of nearby customers and, in many of the graphs, attaining values that are statistically indistinguishable from those of nearby customers. These findings are consistent with the prediction of the theory that proximity mitigates the effects of weak contractual enforcement. ${ }^{28}$

\subsection{Relationships}

The theory considers the possibility that, within each country, some importers are always patient and honor contracts when they are not enforced while others are stochastically myopic. Exporters learn importers' types by interacting with them. These features generate implications for how financing terms change as a trading relationship develops; these are described in Proposition 4. Specifically, importers that have traded more extensively with the exporter in the past should be more likely to transact on post shipment terms and less likely to transact on cash in advance terms. The strength of contractual enforcement should reduce the impact of the development of an extensive trading relationship.

Table 5 displays the results of tests of these ideas. The specifications presented are linear probability models that explain the use of different financing terms. Each specification includes fixed effects for each customer in each country, so the impact of past interaction is identified off of changes in the financing terms offered to particular customers in particular countries. The specifications also include product fixed effects and year fixed effects, and standard errors are clustered by customer.

To measure the extent to which the exporter and importers have interacted in the past, the

\footnotetext{
${ }^{28}$ It is also possible to consider the impact of the interaction of distance and contract enforcement in linear probability models, and the results of these tests are not subject to the challenges of interpreting interaction terms that are associated with multinomial logit models. This approach yields results that are consistent with those that appear in Figure 8. The Online Appendix displays results of using these kinds of specifications.
} 
specifications in the odd numbered columns include the log of sales to a customer prior to a particular transaction, and the specifications in the even numbered columns include the log of the number of past transactions with a customer. These variables are interacted with a dummy equal to one for common law countries to capture the possibility that an established trading relationship has less of an impact in countries with strong institutions. The common law dummy is not included on its own because it is subsumed by the fixed effect for each customer in each country. Specifications also include controls for the log of sales value, the log of sales volume, and the log of GDP per capita.

The dependent variable in the first two columns is a dummy variable equal to one for transactions that occur on cash in advance terms. The -0.0228 coefficient on the log of previous sales in column 1 indicates that transactions with a customer are less likely to occur on cash in advance terms as the value of past transactions with that customer increases. The magnitude of this coefficient implies that a one standard deviation increase in the log of previous sales is associated with a 3.7 percentage point decrease in the use of cash in advance terms. The 0.0216 coefficient on the log of previous sales interacted with the common law dummy offsets the coefficient on the log of previous sales on its own and indicates that the effect of the development of a trading relationship is not operative in common law countries but only in civil law countries. The second column presents results using an alternative measure of the development of the relationship between the exporter and the importer, and the results are similar.

Columns 3 and 4 repeat these specifications but the dependent variable is a dummy equal to one for transactions that occur on letter of credit terms. Although the effects of the development of a relationship on letter of credit use is not explicitly considered in the model, it is considered empirically nonetheless. Measures of the development of a trading relationship do not have a significant effect on the use of this type of financing term in common law or other countries. One possible explanation for this finding is that the exporter and banks may not learn as much about importers in letter of credit transactions as they do in cash in advance transactions because of collateral requirements and limited interaction.

The dependent variable in columns 5 and 6 is a dummy equal to one for transactions that occur on post shipment terms, and the results mirror those in columns 1 and 2. As customers develop a relationship with the exporter, they are more likely to trade on post shipment terms, and the effects of past experience are not significant for transactions with countries with stronger enforcement of contracts. $^{29}$

\footnotetext{
${ }^{29}$ The linear probability models presented in Table 5 have some shortcomings, such as the fact that probabilities are not bounded between zero and one. Running the specifications presented in Table 5 as multinomial logits and graphing estimated probabilities of using alternative terms across different values of the extent of past transactions for customers in common and civil law countries yields results that are consistent with those in Table 5. Such figures appear in the Online Appendix. Table 8 in the Online Appendix also illustrates that the results are robust to dropping letters of credit from the sample to be consistent with the approach taken in the theory. Furthermore, results in Table 9 in the Online Appendix indicate that the findings related to the interaction terms in Table 5 are not specific to using the common law dummy to measure contractual enforcement.
} 


\subsection{The Crisis}

The economic events of late 2008 and early 2009 had a large impact on trade, and the model generates predictions about the impact of the crisis. This section begins by providing some descriptive statistics and then turns to the econometric evidence of the predictions.

Descriptive Statistics Table 6 provides descriptive statistics on how the crisis affected the exporter's sales and the relative use of alternative terms. Even though aggregate sales contracted by $17.6 \%$ in the last quarter of 2008 and first two quarters of 2009 relative to the prior three quarters, the shares of sales that occurred on different terms remained relatively stable. The use of cash in advance terms fell only slightly from $48.0 \%$ to $46.4 \%$. However, the data and theory suggest that the stability in the aggregate use of alternative terms reflects offsetting effects along the extensive and intensive margins for trade that occurred on different payment terms.

In order to analyze these components of trade, it is useful to measure intensive margin growth rates as well as exit and entry rates. Intensive margin growth rates are calculated by identifying those customers that transact with the exporter during the first three quarters of 2008, which is classified as the pre-crisis period, and the subsequent three quarters, which is classified as the crisis period, and then computing the growth in sales to these customers that occur on cash in advance terms, letter of credit terms, and post shipment terms. In order to compute customer exit and entry rates for sales that occur on different terms, customers are first categorized according to the modal transaction terms they use during the precrisis or crisis period. Exit rates are equal to the number of customers that transacted with the exporter on a particular set of terms before the crisis but did not transact with the exporter during the crisis scaled by the number of customers that transacted with the exporter on those terms before the crisis. Entry rates are computed in a similar manner, but the numerator is the number of customers that transacted with the exporter on a particular set of terms during the crisis but did not transact with the exporter before the crisis.

Intensive margin growth rates and exit rates decrease the use of cash in advance terms relative to post shipment terms, but these are offset by entry rates that increases the use of cash in advance terms relative to post shipment terms. More specifically, as indicated in Table 6 intensive margin growth is $-21.2 \%$ for sales that occur on cash in advance terms but $-13.7 \%$ for sales that occur on post shipment terms. The exit rate of customers that traded on cash in advance terms before the crisis is $35.0 \%$, while it is $28.6 \%$ for customers that traded on post shipment terms before the crisis. Theoretically, the differences in exit rates are consistent with the predicted impact of a decline in demand or an increase in the probability that importers face liquidity shocks because cash in advance transactions are the least profitable transactions, and they are less likely to occur when either of these shocks occurs. The differences in intensive margin growth rates are consistent with the predicted impact of an increase in the probability that importers face liquidity shocks because these shocks reduce the profitability of less established trading relationships by larger amounts.

Offsetting these effects, entry rates were $41.2 \%$ for cash in advance customers but only $21.7 \%$ for post shipment term customers. The theory predicts that an increase in the likelihood that an 
importer faces a liquidity shock is associated with an increase in the use of cash in advance terms when transacting with new customers. Taken together, these effects imply that the $-20.4 \%$ growth in the aggregate use of cash in advance terms is only slightly smaller than the $-17.2 \%$ growth in the aggregate use of post shipment terms. ${ }^{30}$

Econometric Evidence The analysis in Tables 7 and 8 analyzes the different effects of the crisis on the intensive and extensive margins of trade more rigorously. The tests presented in Table 7 provide further evidence of the impact of relationships by providing insight on the financing terms offered to new customers, and they inform the question of how financing terms offered to new customers changed during the recent economic crisis. As in Table 5, the dependent variables are dummies equal to one for transactions using cash in advance terms in columns 1 and 2, letter of credit terms in columns 3 and 4 , and post shipment terms in columns 5 and 6 . The specifications include a new customer dummy, a crisis dummy, the interaction of the new customer and crisis dummy, country fixed effects, product fixed effects, and year fixed effects. ${ }^{31}$

The new customer dummy is a dummy equal to one for observations related to the first transaction with a customer and zero otherwise, and the coefficient reveals if financing terms used for new customers are distinctive when compared to those used for existing customers within a particular country. The positive and significant coefficient on this dummy in column 1 indicates that new customers are more likely to transact on cash in advance terms than established customers. The coefficient on the crisis dummy, which is equal to one for transactions that are booked during the crisis, is insignificant, but it is difficult to interpret given the use of year fixed effects. The positive and significant coefficient on the new customer dummy interacted with the crisis dummy is perhaps more telling. Consistent with the theoretical prediction, it indicates that the exporter is more likely to transact with new customers on cash in advance terms during the crisis than it was before the crisis. The test presented in column 2 of Table 7 controls for the log of sales value, the log of sales volume, and the log of GDP per capita, and the results are similar to those presented in column 1.

Tests presented in columns 3 and 4 of Table 7 analyze the extent to which transactions occur on letter of credit terms. The results indicate that trade with new customers is more likely to occur on letter of credit terms. This effect does not appear to be more pronounced during the crisis. Columns 5 and 6 present the findings of analysis of the use of post shipment terms. These mirror the results in columns 1 and 2. New customers are less likely to receive post shipment terms, especially during the crisis. ${ }^{32}$

\footnotetext{
${ }^{30}$ One other feature of the changes in levels of sales across terms is notable. It is very rare for importers that were transacting on post shipment terms before the crisis to switch to the use of cash in advance terms. According to the exporter, once an importer engages in a transaction on post shipment terms, it is very difficult to get that importer to make prepayments for similar transactions.

${ }^{31}$ While the tests presented in Table 5 include customer/country fixed effects, product fixed effects, and year fixed effects, those in Table 7 include country fixed effects, product fixed effects, and year fixed effects. The tests in Table 7 therefore illustrate the terms offered to new as opposed to existing customers and do not indentify differences off of only within customer variation.

${ }^{32}$ As with the analysis in Table 5 , if this analysis is conducted using multinomial logit specifications, graphs of the results are consistent with those presented in Table 7. Such graphs are included in the Online Appendix. It is also
} 
Table 8 presents analysis of the growth of sales to customers that transacted with the exporter in the precrisis period. The dependent variable in columns 1 and 2 captures intensive margin growth and growth due to exit. For customers that remain active, it is equal to the change in sales between the first three quarters of 2008 and the subsequent three quarters scaled by the sum of sales in these two periods, and for customers that only purchase goods in the pre-crisis period, it is set equal to $-1 .{ }^{33}$ These specifications and the others in the table control for GDP growth and changes in the value of the currency in the customer's country, and they include a dummy equal to one for countries that experience a banking crisis. ${ }^{34}$ The 0.1687 coefficient on the share of precrisis sales on post shipment terms variable indicates that customers that were purchasing goods on these terms before the crisis reduce their sales less than other customers during the crisis. The coefficient remains positive and significant in the specification in column 2, which also controls for the $\log$ of precrisis sales value and volume. The 0.1734 coefficient implies that customers that conducted none of their purchases on post shipment terms before the crisis decreased sales by 17.3 percentage points more than customers that conducted all of their sales on these terms.

The next four columns present results for intensive margin growth and growth that is a consequence of exit separately. In columns 3 and 4, the dependent variable is similar to the one used in columns 1 and 2, but observations in which the customer purchases goods before the crisis but not during the crisis are dropped from the sample. The results in column 3 and 4 indicate that customers that transact on post shipment terms experience a smaller decline in sales on the intensive margin than other customers. Columns 5 and 6 present results of linear probability models in which the dependent variable is equal to one for customers that remain active during the crisis, and results of these tests illustrate that customers that purchase a larger share of goods on post shipment terms are more likely to remain active.

Taken together, the analysis in Tables 6, 7, and 8 indicates that the impact of the crisis on trade is shaped by how trade is financed. Importers that were transacting with the exporter on cash in advance terms before the crisis decrease their purchases by larger amounts.

\section{Conclusion}

Existing research does not explain what kinds of financing terms are used to support trade in different circumstances, and how and why these arrangements affect trade. Few theoretical frame-

noteworthy that the increase in the use of cash in advance terms and the decrease in the use of post shipment terms for new customers during the crisis is focused in countries with weak contractual enforcement. This empirical result is implied by the theory and is shown in the Online Appendix. Selection considerations raise issues for the estimates in Table 7. During the crisis, new customers might be different in terms of their risk profile than new customers at other times, thus biasing estimates. Conditioning on the value and volume of the transaction helps address this issue. In addition, it seems reasonable to believe that, if anything, new customers during the crisis are better credit risks than new customers before the crisis, and this difference would work against obtaining the findings in Table 7 .

${ }^{33}$ This approach is used in other work, including Dunne, Roberts, and Samuelson (1989).

${ }^{34}$ GDP growth is measured using quarterly data when such data are available and 2009 growth data when they are not. Exchange rate fluctuations are measured using the change in average exchange rates over the two periods. Banking crises are measured using a dummy equal to one for countries that experience non-borderline local banking crises as documented in Laeven and Valencia (2012). 
works characterize how trade is financed, and a dearth of data limits empirical efforts. This paper attempts to push research on this topic forward. It begins by presenting insights that emerge from a descriptive analysis of detailed transaction-level data from a U.S. exporter. This analysis yields a few basic facts that motivate a model which in turn generates empirical predictions that are tested more rigorously.

Three main conclusions emerge. First, firms that are likely to have the highest costs of obtaining external capital appear to be the ones that need it in order to finance transactions. Descriptive statistics and regression analyses that consider a variety of proxies for the strength of contractual enforcement reveal that importers are more likely to transact on cash in advance terms in countries where contracts are less likely to be honored. $63.8 \%$ of sales to importers in civil law countries occur on cash in advance terms, but only $4.0 \%$ of sales to importers in common law countries occur on these terms. This pattern can be rationalized in a model in which banks in the importing country are more effective than the exporter in pursuing claims against importers.

Second, firms in weak institutional environments are able to overcome the constraints of such environments if they can establish a relationship with their trading partners. Examination of descriptive data and analysis of how financing terms offered to specific customers change over time show that as a relationship develops between trading partners, concerns about contractual enforcement seem to subside, and transactions are more likely to occur on post shipment terms. These findings are consistent with the predictions of a dynamic theoretical framework in which importers are either always patient and do not default when contracts are not enforced or are stochastically myopic and face liquidity shocks with some probability that cause them to default when contracts are not enforced. The exporter learns about the importer's type by transacting with it and becomes more willing to finance transactions through open account terms as a relationship develops.

The third conclusion is that the manner in which trade is financed shapes the impact of macroeconomic and financial crises like the recent one. Using the theoretical framework developed in the paper, crises can be modelled as a decrease in demand and an increase in the likelihood that liquidity shocks occur. Under these circumstances, importers that were transacting on cash in advance terms before the crisis reduce their purchases the most, a pattern that appears in the data.

Additional research on how trade is financed could make novel contributions. Survey evidence suggests that the relative use of alternative financing terms and that the impact of contractual enforcement on the choice of financing terms are similar for other exporters, but further exploration of the generality of the results would be helpful. Analysis of how trade is financed in other settings also could reveal new insights about how contracting problems affect international economic activity and the value of alternative types of collateral. For example, product characteristics might shape financing terms and, in turn, levels of trade. Exporters of commodities might be more willing to trade on letter of credit terms because these goods are a more attractive form of collateral, but exporters of differentiated goods might be more likely to require the use of cash in advance terms. Studies of the firm-level dynamics of trade rarely account for considerations about how trade 
is financed, but financing effects could be significant and correlated with more commonly studied effects. Transitions of firms into and out of international trade activity could reflect liquidity shocks and learning about which firms are creditworthy rather than learning about demand. The growth and productivity of traders could reflect the relaxation of a financial constraint rather than some type of spillover. These topics are left for future research. 


\section{References}

Ai, Chunrong, and Edward C. Norton, 2003, "Interaction Terms in Logit and Probit Models," Economic Letters 80 (1), pp. 123-129.

Ahn, JaeBin, 2011, "A Theory of Domestic and International Trade Finance," working paper.

Ahn, JaeBin, 2014, "Understanding Trade Finance: Theory and Evidence from Transaction-level Data," working paper IMF.

Alessandria, George, Joseph Kaboski, and Virgiliu Midrigan, 2010, "The Great Trade Collapse of 2008-2009: An Inventory Adjustment?" IMF Economic Review 58 (2), pp. 254-294.

Amiti, Mary, and David Weinstein, 2011, "Exports and Financial Shocks," Quarterly Journal of Economics 126 (4), pp.1841-1877.

Antràs, Pol, 2003, "Firms, Contracts, and Trade Structure," Quarterly Journal of Economics 118 (4), pp. $1375-1418$

Antràs, Pol, 2005, "Incomplete Contracts and the Product Cycle," American Economic Review 95 (4), pp. 1054-1073.

Antràs, Pol, and Ricardo Caballero, 2009, "Trade Flows and Capital Flows: A Financial Frictions Perspective," Journal of Political Economy 117 (4), pp. 701-744.

Antràs, Pol, Mihir Desai, and C. Fritz Foley, 2009, "Multinational Firms, FDI Flows and Imperfect Capital Markets," Quarterly Journal of Economics 124 (3), pp. 1171-1219.

Antràs, Pol, and Elhanan Helpman, 2004, "Global Sourcing," Journal of Political Economy 112 (3), pp. $552-580$.

Antràs, Pol and Elhanan Helpman, 2008, "Contractual Frictions and Global Sourcing," forthcoming in E. Helpman, D. Marin, and T. Verdier (eds.), The Organization of Firms in a Global Economy, Harvard University Press.

Araujo, Luis, and Emanuel Ornelas, 2007, "Trust-Based Trade," working paper.

Auboin, Marc, 2009, "Restoring Trade Finance: What the G20 Can Do," in The Collapse of Global Trade, Murky Protectionism, and the Crisis: Recommendations for the G20, ed. Richard Baldwin and Simon Evenett, London: Center for Economic Policy Research.

Banerjee, Abhijit V., and Esther Duflo, 2000, "Reputation Effects and the Limits of Contracting: A Study of the Indian Software Industry," Quarterly Journal of Economics 115 (3), pp. 989-1017.

Baldwin, Richard, and Simon Evenett, eds., 2009, The Collapse of Global Trade, Murky Protectionism, and the Crisis: Recommendations for the G20, London: Center for Economic Policy Research.

Beck, Thorsten, 2002, "Financial Development and International Trade: Is There a Link?" Journal of International Economics 57 (1), pp. 107-131.

Burkart, Mike and Tore Ellingsen, 2004, "In-Kind Finance: A Theory of Trade Credit," American Economic Review 94 (3), pp. 569-590.

Chaney, Thomas, 2005, "Liquidity Constrained Exporters," working paper. 
Chor, Davin and Kalina Manova, 2012, "Off the Cliff and Back? Credit Conditions and International Trade during the Global Financial Crisis," Journal of International Economics 87 (1) pp. 117-133.

Cuñat, Vicente M., 2007, "Trade Credit: Suppliers as Debt Collectors and Insurance Providers," The Review of Financial Studies 20 (2), pp. 491-527.

Desai, Mihir, and C. Fritz Foley, and James R. Hines Jr., 2004, "A Multinational Perspective on Capital Structure Choice and Internal Capital Markets," Journal of Finance 59 (6), pp. 2451-2488.

Djankov, Simeon, Rafael La Porta, Florencio Lopez-De-Silanes, and Andrei Shleifer, 2003, "Courts," Quarterly Journal of Economics 118 (2), pp. 453-517.

Dunne, Timothy, Mark J. Roberts, and Larry Samuelson, 1989, "The Growth and Failure of U.S. Manufacturing Plants," Quarterly Journal of Economics 104 (4), pp. 671-698.

Eaton, Jonathan, Sam Kortum, Brent Neiman, and John Romalis, 2013, "Trade and the Global Recession," working paper.

Foley, C. Fritz, Matthew Johnson, and David Lane, 2010, "Note on International Trade Finance," Harvard Business School Note 9-211-007.

Giannetti, Mariassunta, Mike Burkart and Tore Ellingsen, 2011, "What You Sell Is What You Lend? Explaining Trade Credit Contracts," Review of Financial Studies 24 (4), pp. 1261-1298.

Greene, William, 2010, "Testing Hypotheses about Interaction Terms in Nonlinear Models," Economic Letters 107 (2), pp. 291-296.

Greif, Avner, 1993, "Contract Enforceability and Economic Institutions in Early Trade: The Maghribi Traders' Coalition," American Economic Review 83 (3), pp. 525-548.

Guiso, Luigi, Paola Sapienza, and Luigi Zingales, 2004, "The Role of Social Capital in Financial Development," American Economic Review 94 (3), pp. 526-556.

Guiso, Luigi, Paola Sapienza, and Luigi Zingales, 2009, "Cultural Biases in Economic Exchange?," Quarterly Journal of Economics 124 (3), pp. 1095-1131.

Hart, Oliver and John H. Moore, 1994, "A Theory of Debt Based on the Inalienability of Human Capital," Quarterly Journal of Economics 109 (4), pp. 841-879.

Iacovone, Leonardo, and Veronika Zavacka, 2009, "Banking Crises and Exports: Lessons from the Past," in The Great Trade Collapse: Causes, Consequences and Prospects, edited by Richard Baldwin, VoxEU.Org Books.

Knack, Stephen, and Philip Keefer, 1995, "Institutions and Economic Performance: Cross-Country Tests Using Alternative Institutional Measures," Economics and Politics 7 (3), pp. 207-227.

Kletzer, Kenneth, and Pranab Bardhan, 1987, "Credit Markets and Patterns of International Trade," Journal of Development Economics 27 (1-2), pp. 57-70.

Klapper, Leora, Luc Laeven, and Raghuram Rajan, 2012, "Trade Credit Contracts," The Review of Financial Studies 25 (3), pp. 838-867.

La Porta, Rafael, Florencio Lopez-De-Silanes, and Andrei Shleifer, 2008, "The Economic Consequences of Legal Origins," Journal of Economic Literature 26 (2), pp. 285-332. 
La Porta, Rafael, Florencio Lopez-De-Silanes, Andrei Shleifer, and Robert W. Vishny, 1998, "Law and Finance," Journal of Political Economy 106 (6), pp. 1113-1155.

Laeven, Luc, and Fabián Valencia, 2012, "Systematic Banking Crisis Database: An Update," IMF Working Paper WP/12/163.

Levchenko, Andrei, 2007, "Institutional Quality and International Trade" Review of Economic Studies, 74 (3), pp. 791-819.

Levchenko, Andrei A., Logan Lewis, and Linda L. Tesar, 2010, "The Collapse of International Trade during the 2008-2009 Crisis: In Search of the Smoking Gun," IMF Economic Review 58 (2), pp. 214-253.

Macchiavello, Rocco, 2010, "Development Uncorked: Reputation Acquisition in the New Market for Chilean Wines in the UK," mimeo University of Warwick.

Manova, Kalina, 2008, "Credit Constraints, Equity Market Liberalizations, and International Trade," Journal of International Economics 76 (1), pp. 33-47.

Manova, Kalina, 2013, "Credit Constraints, Heterogeneous Firms, and International Trade," Review of Economic Studies 80 (2), pp. 711-744.

McMillan, John, and Christopher Woodruff, 1999, "Interfirm Relationships and Informal Credit in Vietnam," Quarterly Journal of Economics 114 (4), pp. 1285-1320.

Milgrom, Paul R., Douglas C. North, and Barry R. Weingast, 1990, "The Role of Institutions in the Revival of Trade: The Law Merchant, Private Judges, and the Champagne Fairs," Economics and Politics 2 (1), pp. 1-23.

Nunn, Nathan, 2007, "Relationship-Specificity, Incomplete Contracts and the Pattern of Trade," Quarterly Journal of Economics 122 (2), pp. 569-600.

Ng, Chee K., Janet Kiholm Smith and Richard L. Smith, 1999, "Evidence on the Determinants of Credit Terms Used in Interfirm Trade," The Journal of Finance 54 (3), pp. 1109-1129.

Olsen, Morten, 2013, "How Firms Overcome Weak International Contract Enforcement: Repeated Interaction, Collective Punishment and Trade Finance," working paper.

Paravisini, Daniel, Veronica Rappoport, Philipp Schnabl, and Daniel Wolfenzon, 2012, "Dissecting the Effect of Credit Supply on Trade: Evidence from Matched Credit-Export Data," working paper.

Petersen, Michell A. and Raghuram G. Rajan, 1997, "Trade Credit: Theories and Evidence," The Review of Financial Studies 10 (3), pp. 661-691.

Rauch, James E., 2001, "Business and Social Networks in International Trade," Journal of Economic Literature 39 (4), pp. 1177-1203.

Schmidt-Eisenlohr, Tim, 2013, "Towards a Theory of Trade Finance," Journal of International Economics 91 (1), pp. 96-112.

Stephens, Malcolm, 1998, "Export Credit Agencies, Trade Finance, and South East Asia," IMF Working Paper WP/98/175.

Thomas, Jonathan and Tim Worrall, 1994, "Foreign Direct Investment and the Risk of Expropriation," Review of Economic Studies, 61 (1), pp. 81-108.

Wang, Jian-Ye, and Marcio Ronci, eds., 2006, Access to Trade Finance in Times of Crisis, Washington DC: International Monetary Fund. 


\section{Figure 1}

Share of Aggregate 1996-2009 Sales by Destination Region

Notes: This figure displays the share of aggregated 1996-2009 sales directed to different regions of the world.

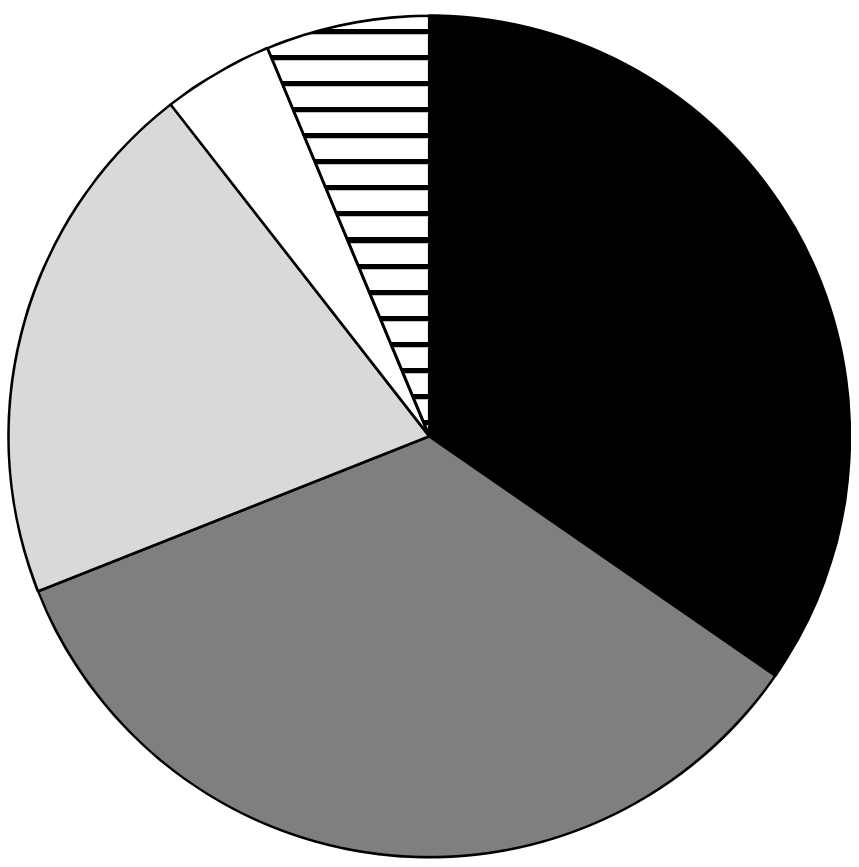

East Asia and Pacific

$\square$ Latin America and Caribbean

口Europe and Central Asia

$\square$ North America

口Other

Figure 2

Share of Aggregate 1996-2009 Sales by Product

Notes: This figure displays the share of aggregated 1996-2009 sales by product category.

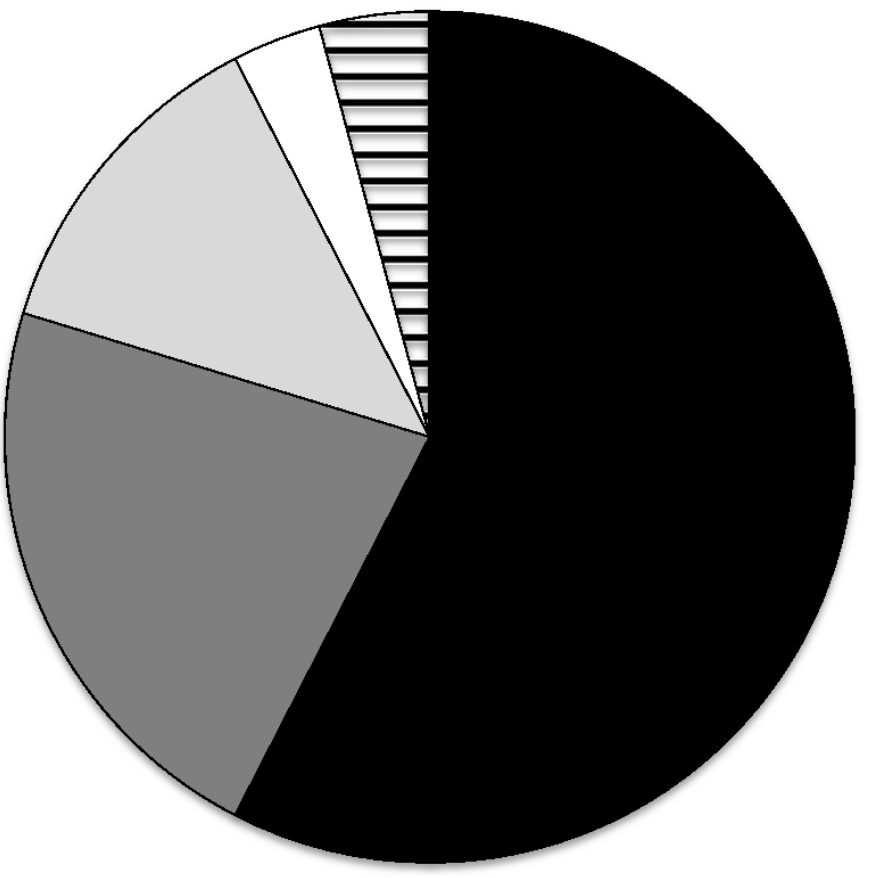

- Poultry

$\square$ Pork

$\square$ Other Meat

$\square$ Fruits and Vegetables

$\square$ Other 
Figure 3

\section{Financing Terms and the Enforcement of Contracts}

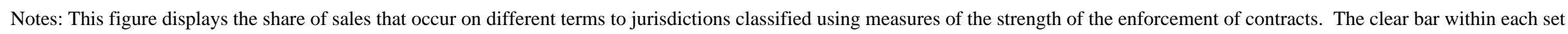

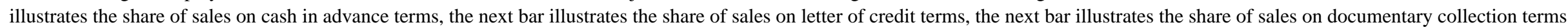

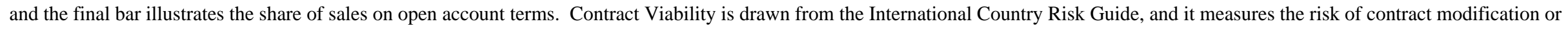

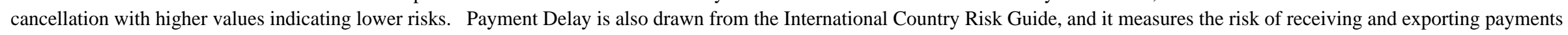

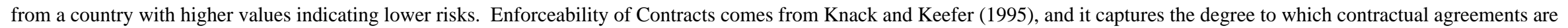
honored with higher values indicating higher enforcement.

\section{Panel A: Legal Origin}

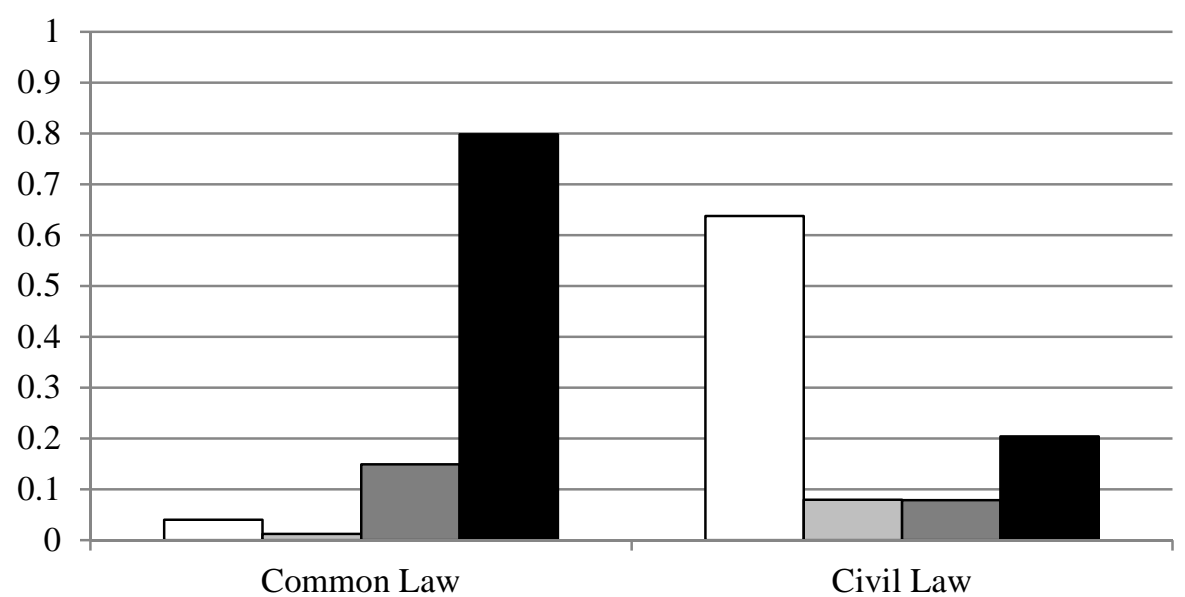

Panel C: Payment Delay

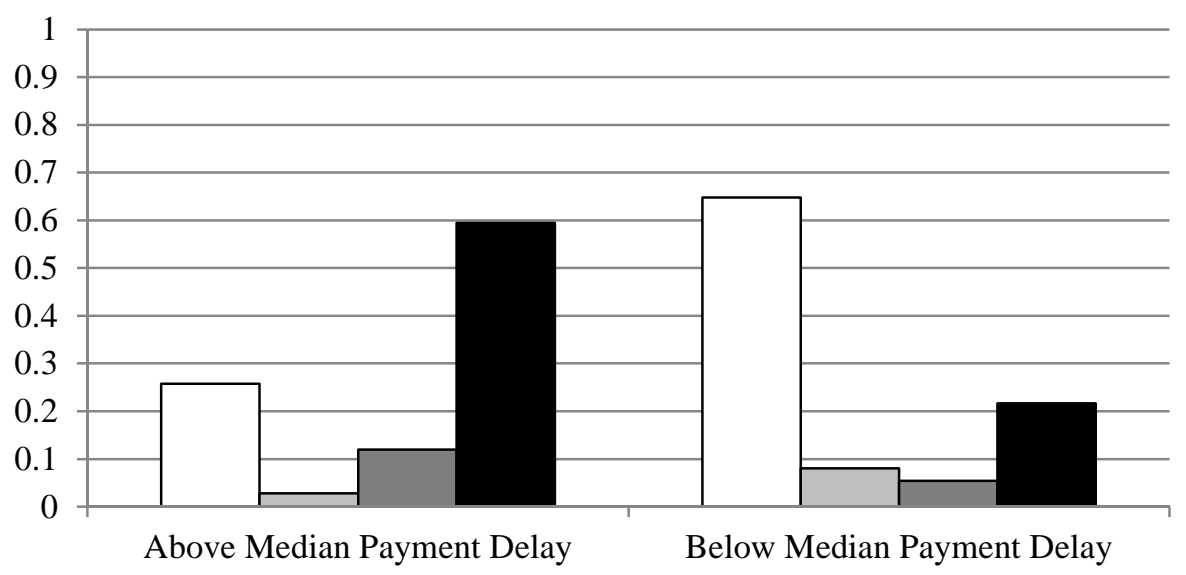

\section{Panel B: Contract Viability}

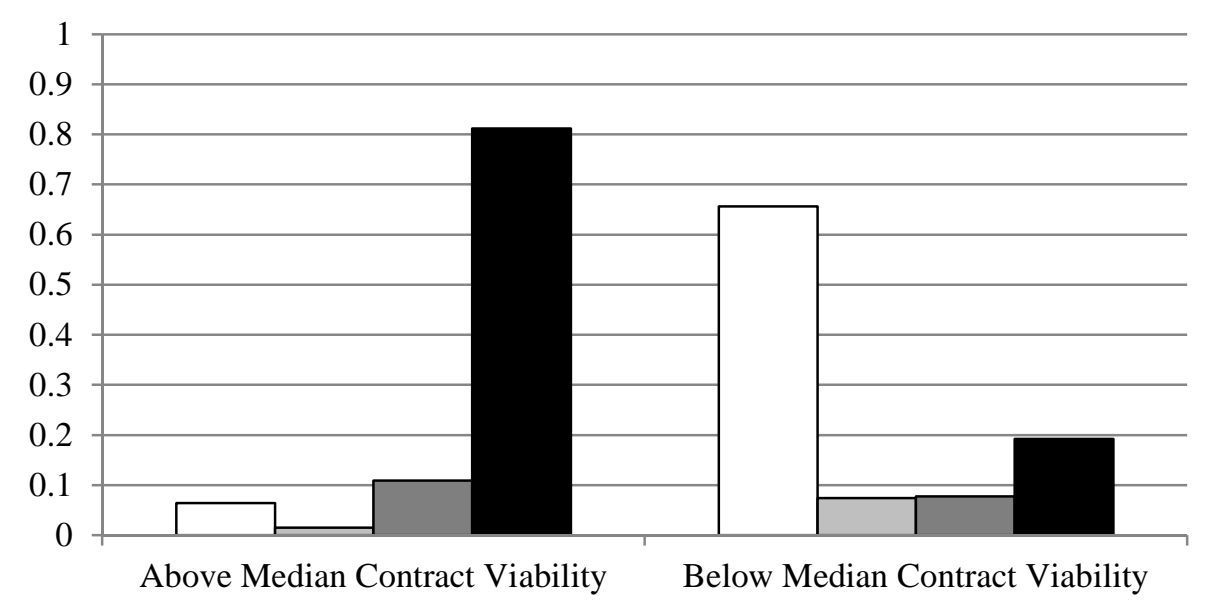

Panel D: Enforceability of Contracts

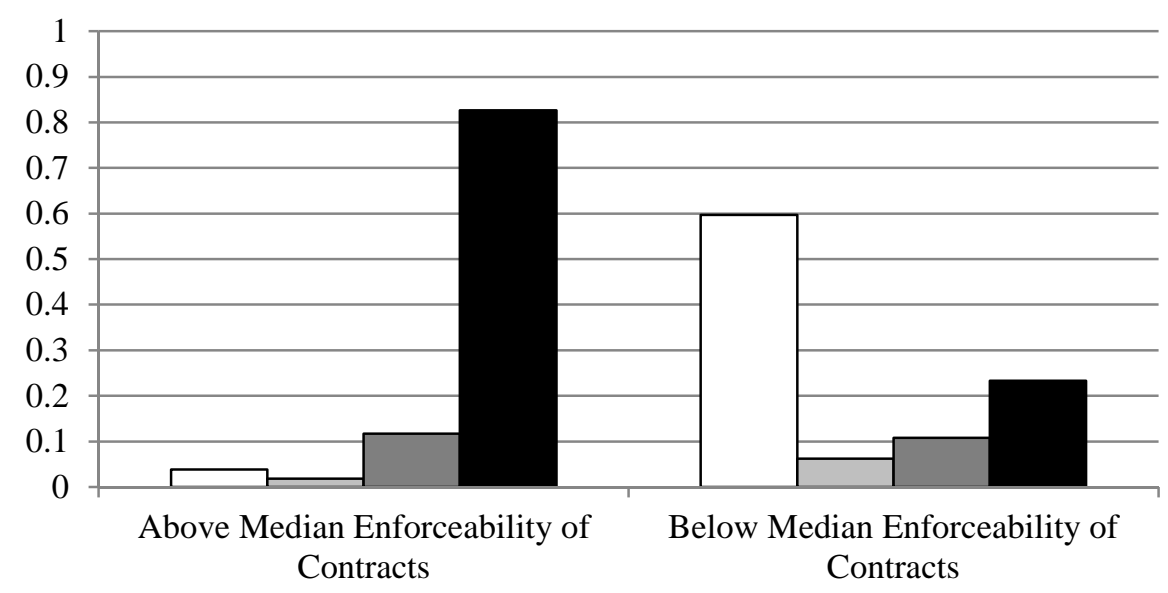

$\square$ Documentary Collections $\quad$ Open Account 
|lı|ı.. 
Figure 5

\section{Comparison with FCIB Survey Data}

Notes: This figure displays data from two sources on the use of open account terms for sales in 2009. The top panel shows the average extent to which open account terms are the top payment method used for sales to jurisdictions classified using measures of the strength of the enforcement of contracts. It is constructed using data from FCIB, a trade association of export credit and trade finance specialists. The lower panel shows similar measures computed using the primary data analyzed throughout the paper. The first two bars respectively illustrate common law and civil law countries, the next two are for countries with above and below median measures of contract viability, the next two are for countries with above and below median measures of payment delays, and the last two are for countries with above and below median measures of the enforceability of contracts. Contract Viability is drawn from the International Country Risk Guide, and it measures the risk of contract modification or cancellation with higher values indicating lower risks. Payment Delay is also drawn from the International Country Risk Guide, and it measures the risk of receiving and exporting payments from a country with higher values indicating lower risks. Enforceability of Contracts comes from Knack and Keefer (1995), and it captures the degree to which contractual agreements are honored with higher values indicating higher enforcement.

\section{Panel A: FCIB Survey Data}

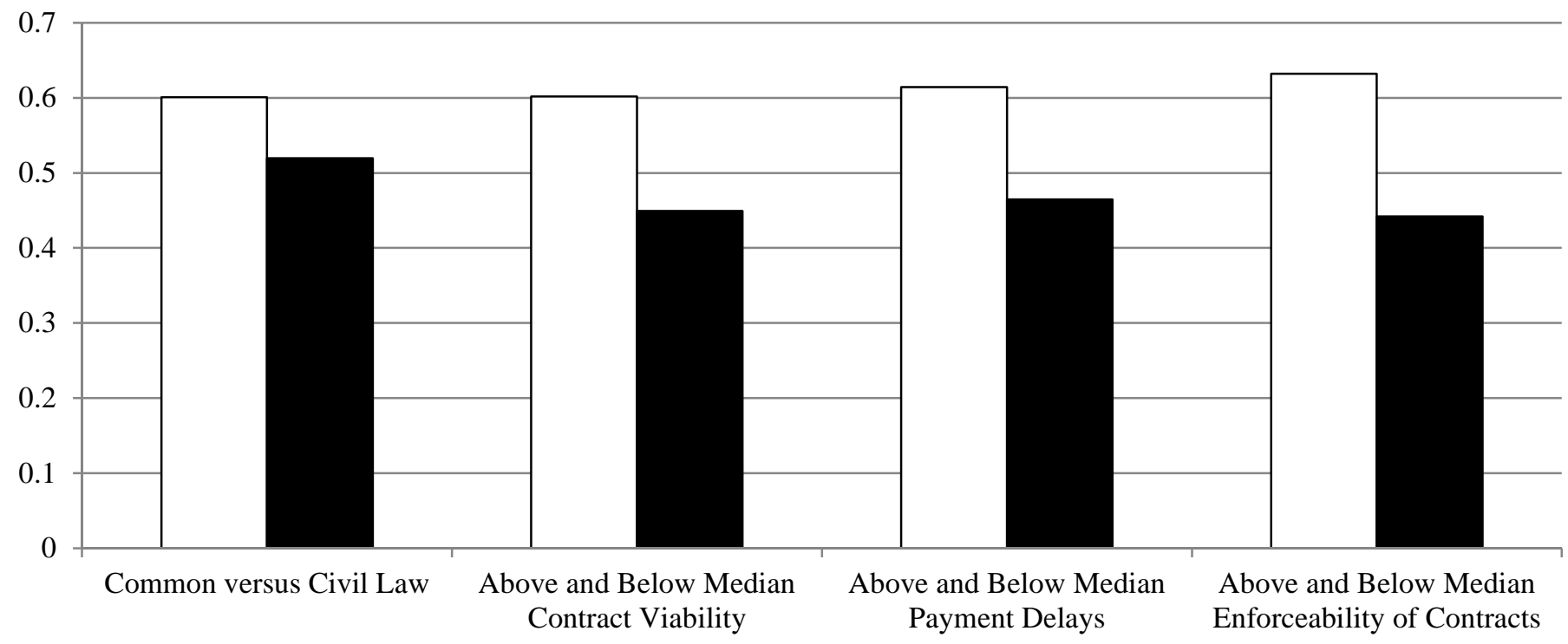

Panel B: Exporter Data

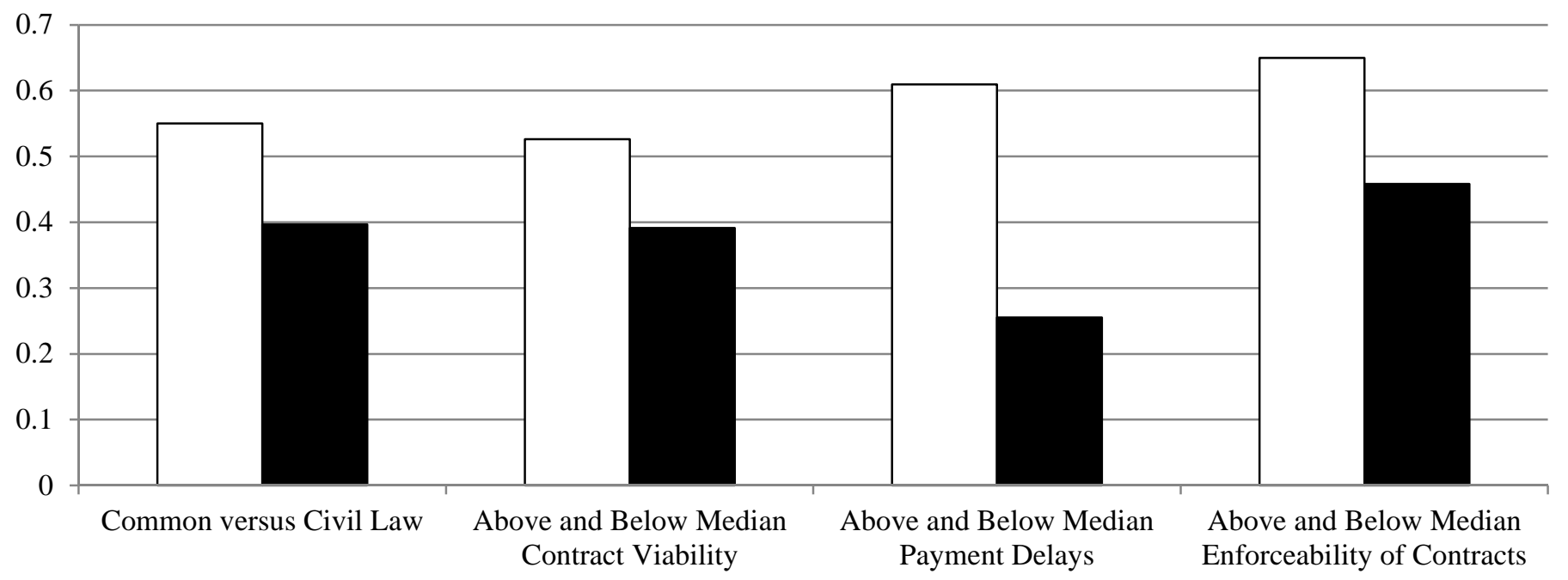




\section{Figure 6}

\section{Financing Terms, Repeated Interactions, and a Fall in Demand}

This figure illustrates the relationship between the expected profitability of transactions under post shipment terms and cash in advance terms as a function of the number of past transactions. The dashed curves indicate the impact of a fall in demand.

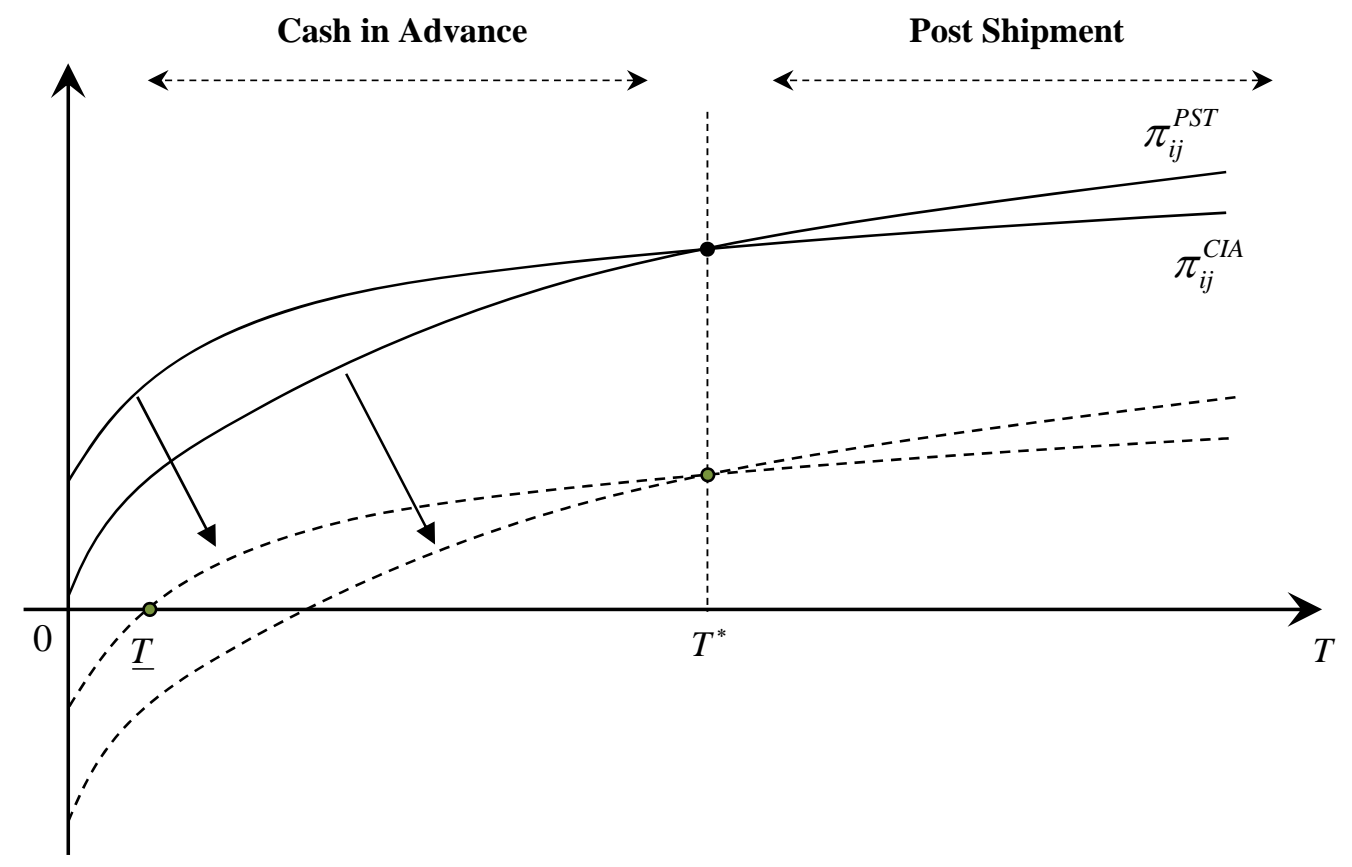

Figure 7

\section{Financing Terms, Repeated Interactions, and a Fall in the Share of Trustworthy Importers}

This figure illustrates the relationship between the expected profitability of transactions under post shipment terms and cash in advance terms as a function of the number of past transactions. The dashed curves indicate the impact of a fall in the share of trustworthy importers.

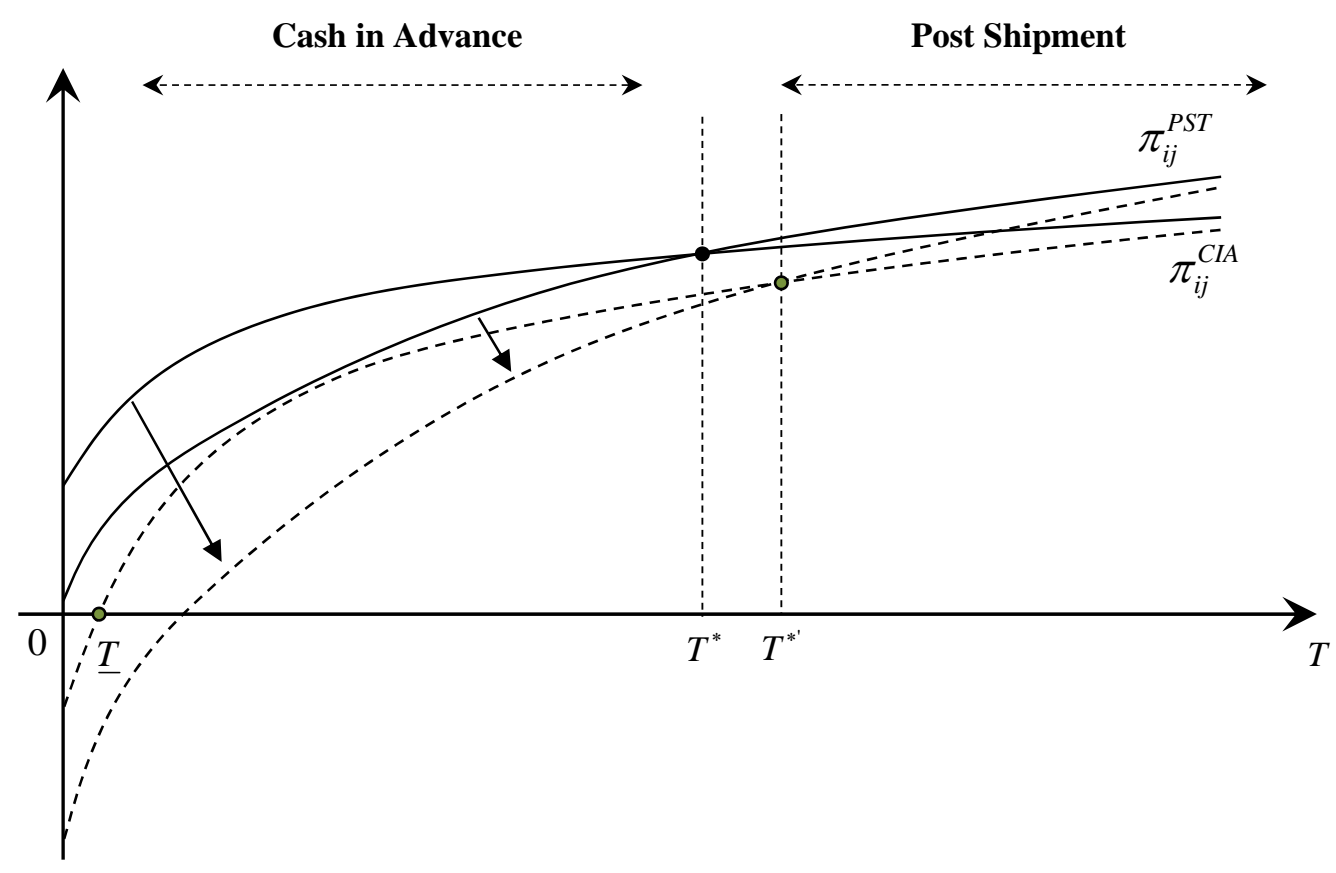




\section{Figure 8}

\section{Financing Terms, Enforcement of Contracts, and Distance}

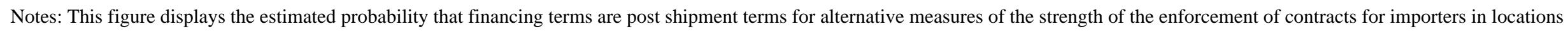

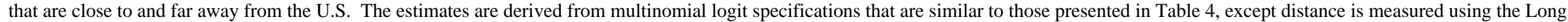

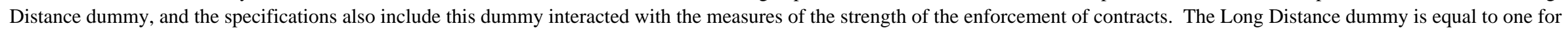

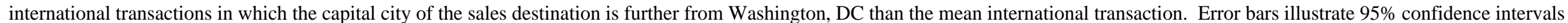
computed on the basis of heteroskedasticity-consistent standard errors that correct for clustering at the country level.

\section{Panel A: Legal Origin}

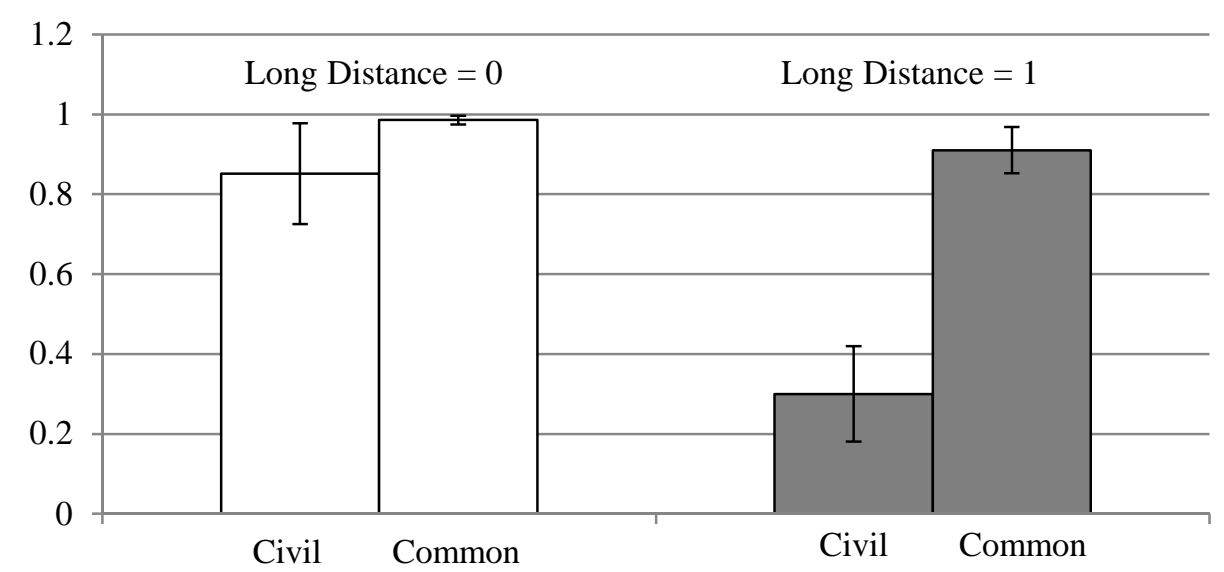

Panel C: Payment Delay

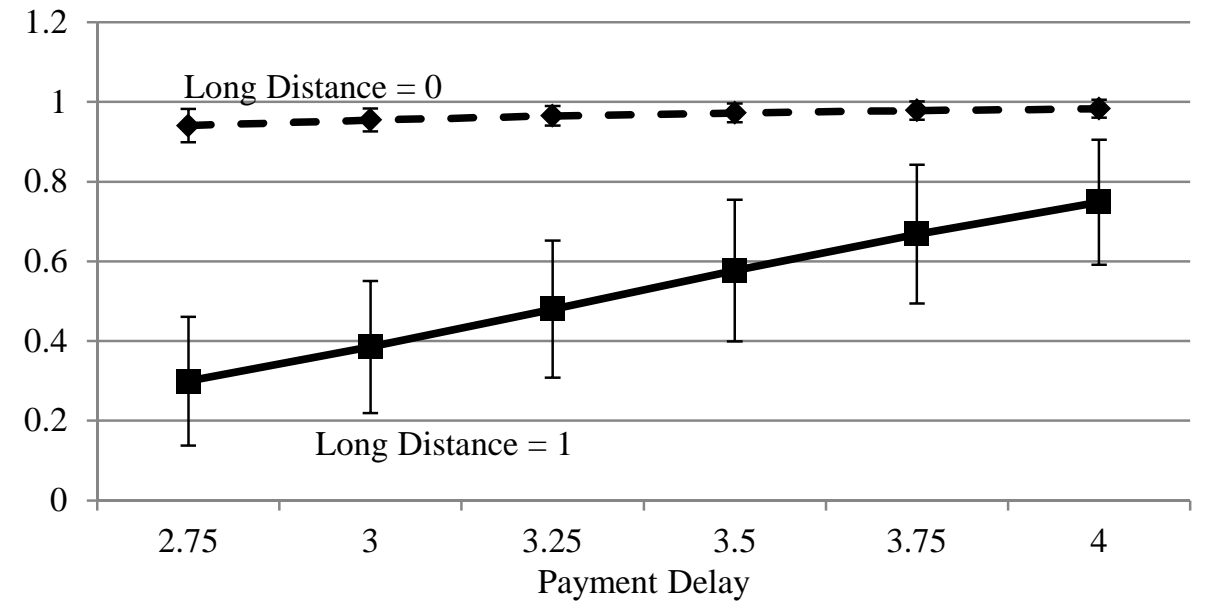

Panel B: Contract Viability

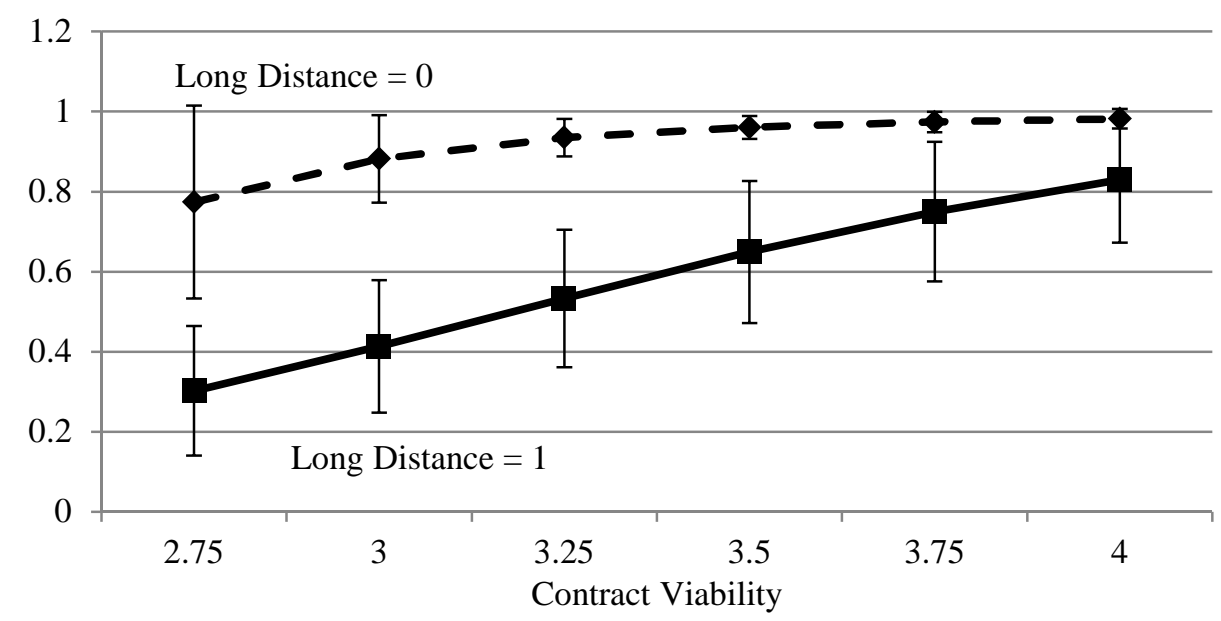

Panel D: Enforceability of Contracts

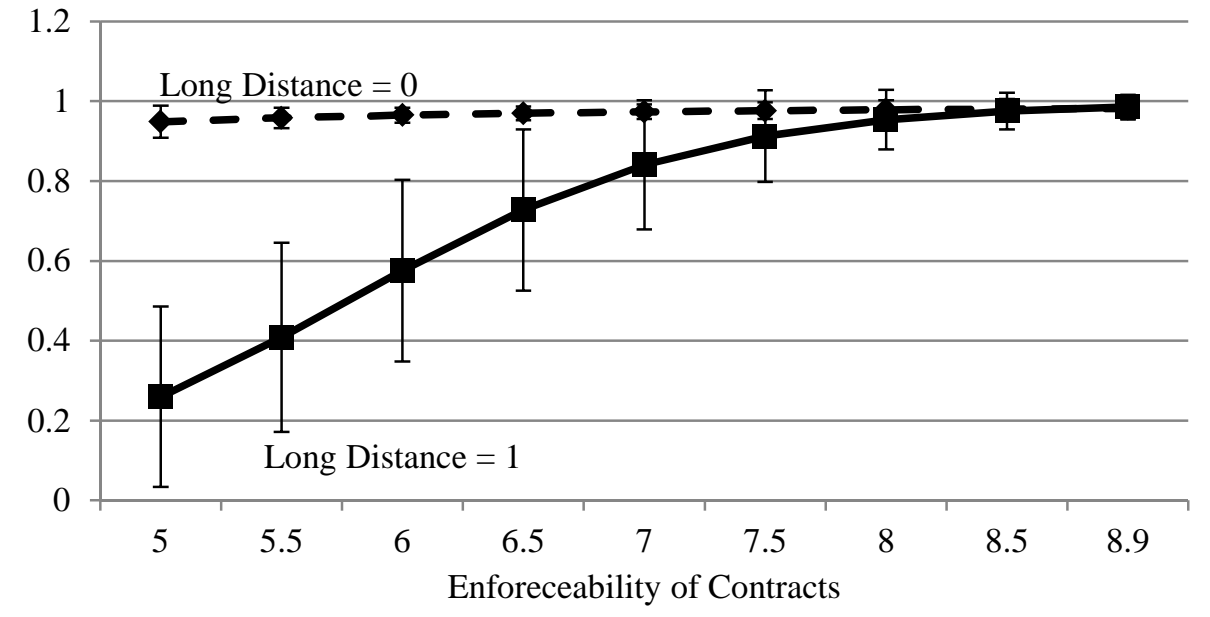




\section{Figure 8 (Continued)}

Panel E: Confidence in Legal System

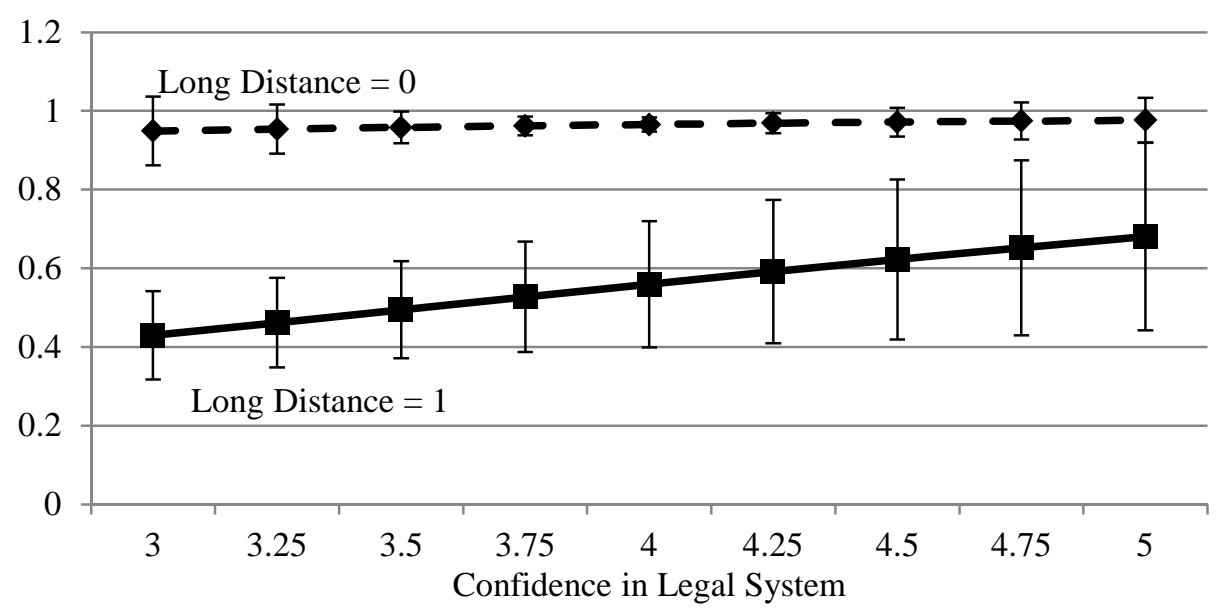

\section{Panel G: Private Credit}

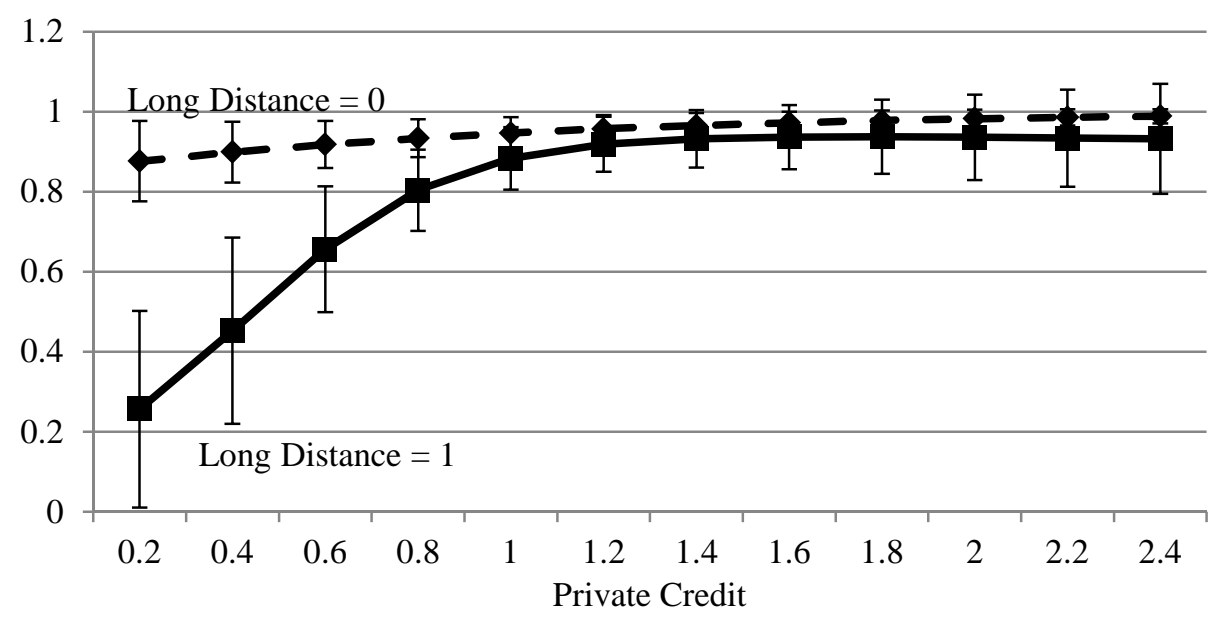

Panel F: Duration of Legal Procedure

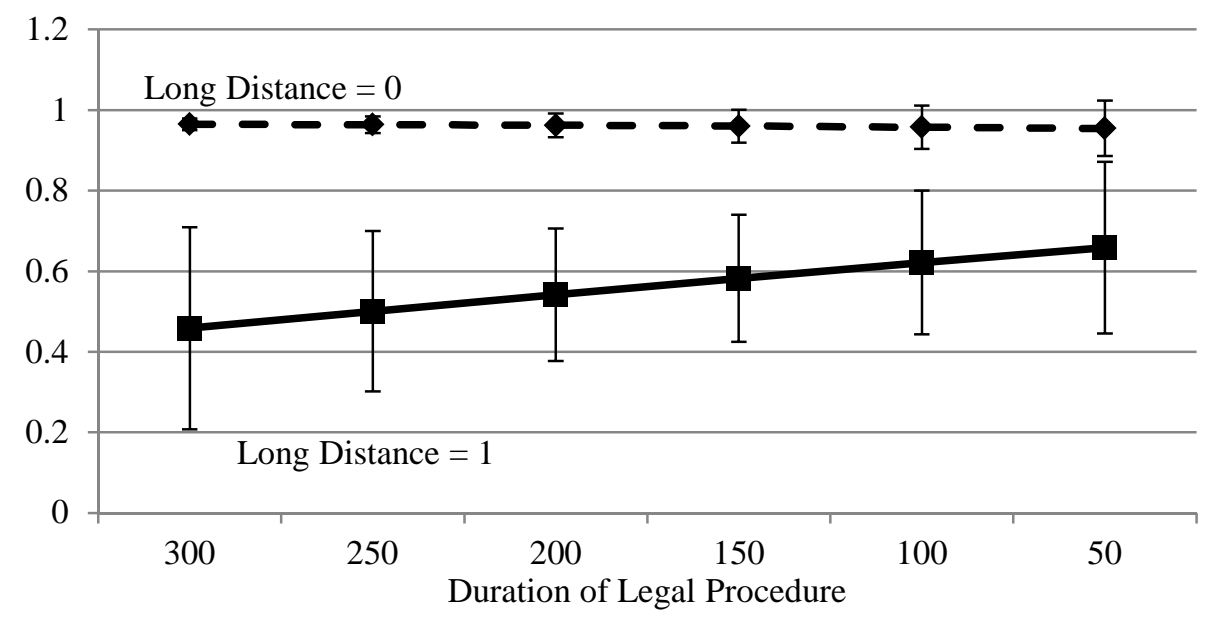

Panel H: Stock Market Capitalization

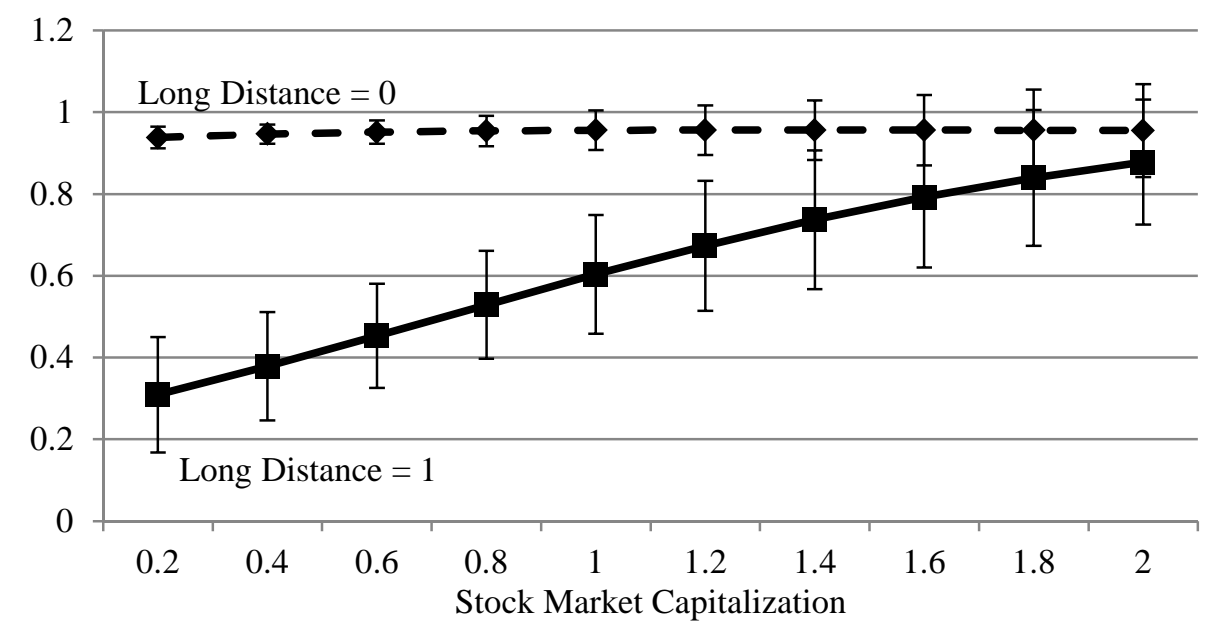


Table 1

\section{Categories of Financing Terms}

Notes: This table displays the twenty most commonly used financing terms and how these terms are assigned to the four categories of terms that appear in the first row.

\begin{tabular}{|c|c|c|c|}
\hline Cash In Advance & Letter of Credit & Documentary Collection & Open Account \\
\hline Wire transfer in advance & Letter of credit & Sight draft & Net 7 days after arrival \\
\hline $\begin{array}{l}\text { Wire transfer upon } \\
\text { receiving fax }\end{array}$ & & & Net 7 allow 21 \\
\hline $\begin{array}{l}20 \% \text { deposit, } 80 \% \text { wire } \\
\text { transfer in advance }\end{array}$ & & & Net 7 allow 30 \\
\hline $\begin{array}{c}10 \% \text { wire transfer in } \\
\text { advance, } 90 \% \text { prior to } \\
\text { arrival }\end{array}$ & & & Net 14 days after arrival \\
\hline $\begin{array}{c}10 \% \text { wire transfer in } \\
\text { advance, } 90 \% 3 \text { days } \\
\text { prior to arrival }\end{array}$ & & & Net 15 days after arrival \\
\hline $\begin{array}{l}30 \% \text { deposit, } 70 \% 7 \text { days } \\
\text { prior to arrival }\end{array}$ & & & Net 21 days after arrival \\
\hline $\begin{array}{c}\text { 30\% deposit, } 70 \% \\
\text { estimated time of arrival }\end{array}$ & & & $\begin{array}{l}\text { Net } 21 \text { days after } \\
\text { delivery }\end{array}$ \\
\hline $\begin{array}{l}\text { 15\% deposit, } 85 \% \text { prior } \\
\text { to arrival }\end{array}$ & & & $\begin{array}{c}\text { Net } 30 \text { days after arrival } \\
\text { Net } 30 \text { days after } \\
\text { delivery }\end{array}$ \\
\hline & & & $\begin{array}{c}\text { Net } 45 \text { days from bill of } \\
\text { lading date }\end{array}$ \\
\hline
\end{tabular}

Table 2

Relative Use of Financing Terms

Notes: This table displays the share of sales that occur on different financing terms for all customers and new customers.

\begin{tabular}{ccccc}
\hline Sample & $\begin{array}{c}\text { Cash in Advance } \\
\text { Share }\end{array}$ & $\begin{array}{c}\text { Letter of Credit } \\
\text { Share }\end{array}$ & $\begin{array}{c}\text { Documentary } \\
\text { Collection Share }\end{array}$ & $\begin{array}{c}\text { Open Account } \\
\text { Share }\end{array}$ \\
\hline All Customers & $42.4 \%$ & $5.5 \%$ & $10.7 \%$ & $41.3 \%$ \\
New Customers & $51.3 \%$ & $14.0 \%$ & $12.0 \%$ & $22.6 \%$
\end{tabular}




\section{Table 3}

\section{Descriptive Statistics}

Notes: The Cash in Advance Dummy, Letter of Credit Dummy, and Post Shipment Dummy are dummies equal to one for transactions that occur on cash in advance, letter of credit, or post shipment terms, respectively. Common Law Dummy is a dummy equal to one for countries with a common law legal origin. Contract viability is drawn from the International Country Risk Guide, and it measures the risk of contract modification or cancellation with higher values indicating lower risks. Payment Delay is also drawn from the International Country Risk Guide, and it measures the risk of receiving and exporting payments from a country with higher values indicating lower risks. Enforceability of Contracts comes from Knack and Keefer (1995), and it captures the degree to which contractual agreements are honored with higher values indicating higher enforcement. Confidence in Legal System is drawn from a World Bank Survey of managers on the degree to which they believe the system will uphold contracts and property rights in a business dispute, and higher values imply greater confidence. Duration of Legal Procedure is taken from Djankov et al. (2003), and it measures the total estimated duration in calendar days to pursue a claim on a bounced check. Private Credit is the ratio of private credit by deposit money banks and other financial institutions to GDP, and Stock Market Capitalization is the value of listed shares to GDP. Distance measures the distance from Washington DC to the capital city of a country. Sales value is measured in dollars, and sales volume is measured in pounds. Log of Previous Sales is the log of aggregate sales to a customer location prior to a transaction, and Log of Number of Previous Transactions is the log of the count of transactions to a customer location prior to a transaction. Growth: All Customers is the growth in sales to customers measured as the change in sales between the first three quarters of 2008, or the precrisis period, and the subsequent three quarters, or the crisis period, scaled by the sum of sales in the precrisis and crisis periods. This growth rate is equal to -1 for customers that purchase goods in the precrisis period but not the crisis period, but such customers are excluded from the sample in computing Growth: Customers that Remain Active. Customer Remains Active Dummy is a dummy equal to one for customers that purchase goods in the precrisis and crisis periods and zero for customers that only purchase goods in the precrisis period. Share of Pre-crisis Sales on Post Shipment Terms measures the share of purchases by a customer during the precrisis period that occurred on post shipment terms. GDP Growth measures gdp growth in the customer's country in between the precrisis and crisis period, and local currency depreciation measures depreciation in the customer's country over the same horizon. Local Banking Crisis is a dummy equal to one for countries that experience non-borderline local banking crises as documented in Laeven and Valencia (2012). Log of Precrisis Sales Value is the log of precrisis sales measured in millions of dollars, and Log of Precrisis Sales Volume is the log of precrisis sales measured in pounds.

Cash in Advance Dummy
Letter of Credit Dummy
Post Shipment Dummy
Common Law Dummy
Contract Viability
Payment Delay
Enforceability of Contracts
Confidence in Legal System
Duration of Legal Procedure
Private Credit
Stock Market Capitalization
Log of Distance
Log of GDP per capita
Log of Sales Value
Log of Sales Volume
Log of Previous Sales
Log of Number of Previous Transactions
Growth: All Customers
Growth: Customers that Remain Active
Customer Remains Active Dummy
Share of Precrisis Sales on Post Shipment Terms
GDP Growth
Local Currency Depreciation
Local Banking Crisis
Log of Precrisis Sales Value
Log of Precrisis Sales Volume

$\begin{array}{cc}\text { Mean } & \text { Standard Deviation } \\ 0.1735 & 0.3787 \\ 0.0173 & 0.1305 \\ 0.8092 & 0.3930 \\ 0.7067 & 0.4553 \\ 3.6607 & 0.5043 \\ 3.6492 & 0.6242 \\ 7.8378 & 1.5029 \\ 4.1307 & 0.3995 \\ 101.28 & 97.24 \\ 1.4007 & 0.6816 \\ 1.1072 & 0.5300 \\ 7.6738 & 1.3468 \\ 2.3190 & 0.9562 \\ 7.6225 & 2.2341 \\ 7.4349 & 2.9299 \\ 15.5702 & 1.6128 \\ 7.2670 & 2.4569 \\ -0.4056 & 0.5325 \\ -0.1225 & 0.4123 \\ 0.6774 & 0.4678 \\ 0.5398 & 0.4953 \\ -0.0067 & 0.0580 \\ 0.0680 & 0.0957 \\ 0.1333 & 0.3401 \\ 12.5017 & 1.6351 \\ 12.6269 & 1.8062 \\ & \end{array}$


Table 4

\section{Financing Terms and Enforcement of Contacts}

Notes: This table displays estimates of coefficients from multinomial logit specifications that explain the choice to use cash in advance, letter of credit, or post shipment financing terms. The specifications include one of the country variables listed in the first column, the log of distance, the log of GDP per capita, product fixed effects, and year fixed effects. Common Law Dummy is a dummy equal to one for countries with a common law legal origin. Contract Viability is drawn from the International Country Risk Guide, and it measures the risk of contract modification or cancellation with higher values indicating lower risks. Payment Delay is also drawn from the International Country Risk Guide, and it measures the risk of receiving and exporting payments from a country with higher values indicating lower risks. Enforceability of Contracts comes from Knack and Keefer (1995), and it captures the degree to which contractual agreements are honored with higher values indicating higher enforcement. Confidence in Legal System is drawn from a World Bank Survey of managers on the degree to which they believe the system will uphold contracts and property rights in a business dispute, and higher values imply greater confidence. Duration of Legal Procedure is taken from Djankov et al. (2003), and it measures the total estimated duration in calendar days to pursue a claim on a bounced check. Private Credit is the ratio of private credit by deposit money banks and other financial institutions to GDP, and Stock Market Capitalization is the value of listed shares to GDP. Distance measures the distance from Washington DC to the capital city of a country. Standard errors that correct for clustering by country appear in parentheses below coefficients. ***, **, and * denote significance at the 1,5 , and 10 percent levels, respectively.

\begin{tabular}{lccc}
\hline \multicolumn{1}{c}{ Type of Financing Terms: } & $\begin{array}{c}\text { Cash in Advance vs. Post } \\
\text { Shipment }\end{array}$ & $\begin{array}{c}\text { Letter of Credit vs. Post } \\
\text { Shipment }\end{array}$ & $\begin{array}{c}\text { Cash in Advance vs. } \\
\text { Letter of Credit }\end{array}$ \\
\hline Common Law Dummy & -3.3423 & -3.0340 & -0.3083 \\
& $(0.4633)^{* * *}$ & $(0.8000)^{* * *}$ & $(0.9612)$ \\
Contract Viability & -2.6745 & -2.6533 & -0.0211 \\
& $(0.4837)^{* * *}$ & $(1.1931)^{* *}$ & $(1.0954)$ \\
Payment Delay & -1.3338 & -2.3326 & 0.9988 \\
& $(0.5843)^{* *}$ & $(0.8307)^{* * *}$ & $(0.7334)$ \\
Enforceability of Contracts & -0.5916 & -0.8264 & 0.3068 \\
& $(0.3023)^{*}$ & $(0.3580)^{* *}$ & $(0.4898)$ \\
Confidence in Legal System & -1.2219 & -0.9257 & -0.2962 \\
& $(0.3897)^{* * *}$ & $(0.1847)^{* * *}$ & $(0.3833)$ \\
Duration of Legal Procedure & 0.0002 & 0.0027 & -0.0026 \\
Private Credit & $(0.0024)$ & $(0.0016)^{*}$ & $(0.0025)$ \\
Stock Market Capitalization & -2.1139 & -0.3026 & -1.8113 \\
& $(0.6568)^{* * *}$ & $(0.4313)$ & $(0.6915)^{* * *}$ \\
\hline
\end{tabular}


Table 5

\section{Effects of Relationships on Financing Terms}

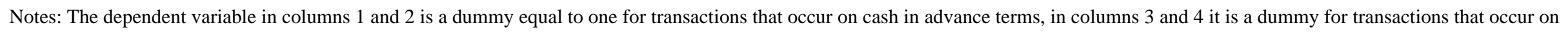

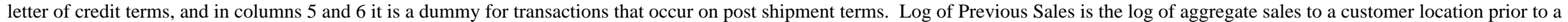

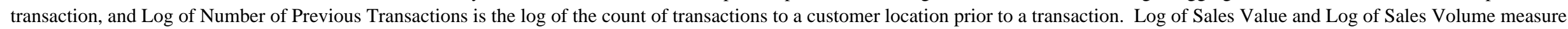

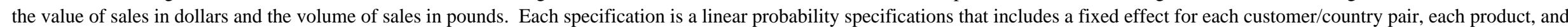

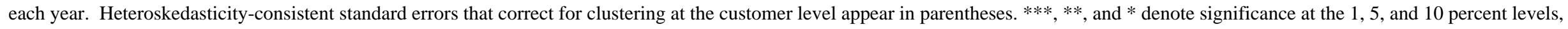
respectively.

Dependent Variable:

Log of Previous Sales

Log of Previous Sales * Common Law

Dummy

Log of Number of Previous Transactions

Log of Number of Previous Transactions * Common Law Dummy

Log of Sales Value

Log of Sales Volume

Log of GDP per Capita

Customer/Country Fixed Effects?

Product Fixed Effects?

Year Fixed Effects?

No. of Obs.

R-Squared
Dummy if Cash in Advance Terms

(1)

$$
\begin{gathered}
-0.0228 \\
(0.0081)^{* * *} \\
0.0216 \\
(0.0092)^{* *}
\end{gathered}
$$

(2)

Dummy if Letter of Credit Terms

-0.0188
$(0.0062)^{* * *}$
0.0190
$(0.0074)^{* *}$

$-0.0002$

(0.0005)

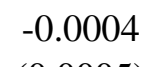

(0.0005)

$-0.0003$

(0.0007)

$-0.0002$

(0.0007)

0.0000

(0.0611)

$-0.0098$

(0.0600)

Y
Y
Y

567,313

0.9500

\section{Y}

$\mathrm{Y}$

Y

567,357

0.9497
Y

Y

$\mathrm{Y}$

567,357

0.8398
0.0043

(0.0035)

$-0.0032$

(0.0029)

(4)

0.0186

$(0.0087)^{* *}$

$-0.0184$

(0.0095)*

0.0036

(0.0034)

$-0.0033$

(0.0032)

0.0010

(0.0007)

0.0011

(0.0007)

$-0.0005$

(0.0004)

$-0.0006$

(0.0005)

$-0.0175$

(0.0157)

$-0.0164$

(0.0153)

$\mathrm{Y}$
$\mathrm{Y}$
$\mathrm{Y}$

567,313

0.8398
0.0151

$(0.0068)^{* *}$

$-0.0157$

$(0.0078)^{* *}$

$-0.0009$

(0.0007)

$-0.0007$

(0.0007)

0.0008

(0.0008)

0.0007

(0.0008)

0.0175

(0.0611)

0.0262

(0.0594)

Y

$\mathrm{Y}$
$\mathrm{Y}$

Y

567,313

0.9426
$\mathrm{Y}$

$\mathrm{Y}$

Y

567,357

567,357
0.9424 
Table 6

\section{Growth and its Components During the Crisis}

Notes: This table presents information on the use of alternative terms and on changes in the intensive and extensive margins of trade during the recent financial crisis. The crisis period is defined as the last quarter of 2008 and the first two quarters of 2009. The precrisis period is defined as the first three quarters of 2008. Shares indicate the shares of aggregate sales that occur on different terms. Intensive margin growth rates are computed by identifying customers that transact with the exporter during the precisis and crisis periods and measuring changes in sales to these customers that occur on cash in advance, letter of credit, or post shipment terms. Exit and entry rates are computed by first categorizing customers according to the modal transaction terms they use in the precrisis or crisis period. Exit rates are equal to the number of customers who transacted with the exporter using a particular payment term during the precrisis period but not the crisis period scaled by the number of customers who transacted using that same payment term during the precrisis period. Entry rates are equal to the number of customers who transacted with the exporter using a particular payment term during the crisis period but not the precrisis period scaled by the number of customers who transacted using that same payment term during the precrisis period. Overall Growth measures the change in total sales that occur under a particular payment terms between the precrisis and crisis period.

Cash in Advance $\quad$ Letter of Credit $\quad$ Post Shipment Terms

Shares

Precrisis

Crisis

Intensive Margin

Growth

Exit Rate

Entry Rate

Overall Growth
$48.0 \%$

$46.4 \%$

$-21.2 \%$

$35.0 \%$

$41.3 \%$

$-20.4 \%$
$4.3 \%$

$5.6 \%$

$14.1 \%$

$50.0 \%$

$32.6 \%$

$8.8 \%$
$47.7 \%$

$48.0 \%$

$-13.7 \%$

$28.6 \%$

$21.7 \%$

$-17.2 \%$ 
Table 7

\section{Financing Terms for New Customers}

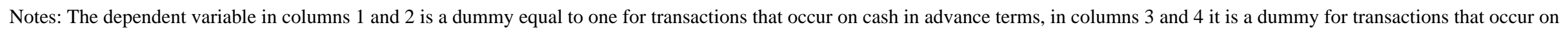

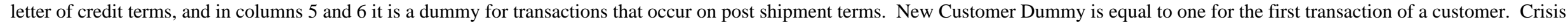

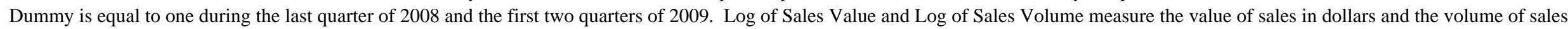

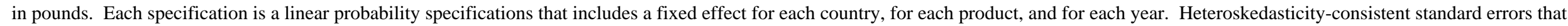
correct for clustering at the customer level appear in parentheses. ***, **, and * denote significance at the 1, 5, and 10 percent levels, respectively.

\section{Dependent Variable:}

rable:

New Customer Dummy

Crisis Dummy

New Customer Dummy * Crisis Dummy

Log of Sales Value

Log of Sales Volume

Log of GDP per Capita

Country Fixed Effects?

Product Fixed Effects?

Year Fixed Effects?

No. of Obs.

R-Squared
Dummy if Cash in Advance Terms

Dummy if Letter of Credit Terms

Dummy if Post Shipment Terms
(2)

0.0963
$(0.0116)^{* * *}$

$$
\begin{gathered}
0.0016 \\
(0.0029) \\
0.0799 \\
(0.0330)^{* *}
\end{gathered}
$$

0.0962

0.0004
$(0.0023)$$$
0.0673
$$

$(0.0121)^{* * *}$$$
(0.0340)^{* *}
$$

0.0511

$-0.0436$

$-0.0071$

$(0.0032)^{* *}$

0.0041

$(0.0018)^{* * *}$

$\begin{array}{cc}\mathrm{Y} & \mathrm{Y} \\ \mathrm{Y} & \mathrm{Y} \\ \mathrm{Y} & \mathrm{Y} \\ 579,008 & 571,920 \\ 0.7798 & 0.8009\end{array}$

(3)

0.0209
$(0.0072) * * *$

-0.0003
$(0.0010)$

(0.0010)

0.0232

(0.0174)
(4)

(5)

(6)

0.0219
$(0.0073)^{* * *}$
-0.0002
$(0.0010)$
0.0225
$(0.0178)$
-0.0021
$(0.0109)$
0.0005
$(0.0011)$
0.0002
$(0.0010)$

$-0.1172$

$(0.0118)^{* * *}$

$-0.0013$

(0.0029)

$-0.1031$

$(0.0338)^{* * *}$

$\mathrm{Y}$
$\mathrm{Y}$
$\mathrm{Y}$
579,008
0.4996

$\mathrm{Y}$
$\mathrm{Y}$
$\mathrm{Y}$
571,920
0.5007

$\mathrm{Y}$
$\mathrm{Y}$
$\mathrm{Y}$
579,008
0.7752




\section{Table 8}

\section{Effects of Crisis on Growth by Financing Terms}

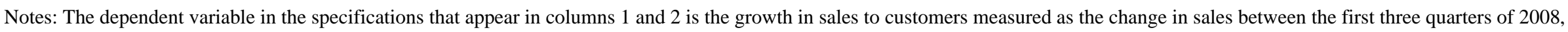

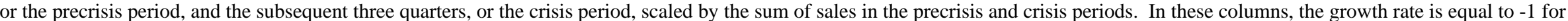
customers that purchase goods in the precrisis period but not the crisis period, but such customers are excluded from the sample in columns 3 and 4 which analyze growth on the intensive

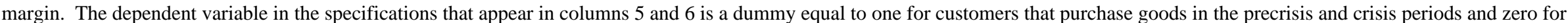

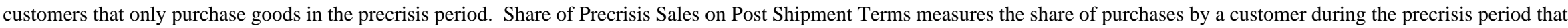

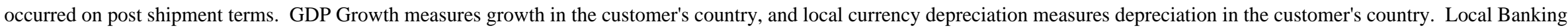
Crisis is a dummy equal to one for countries that experience non-borderline local banking crises as documented in Laeven and Valencia (2012). Log of Precrisis Sales Value is the log of precrisis sales measured in millions of dollars, and Log of Precrisis Sales Volume is the log of precrisis sales measured in pounds. The specifications are OLS specifications, and heteroskedasticity consistent standard errors appear in parentheses. ${ }^{* *}, * *$, and * denote significance at the 1,5 , and 10 percent levels, respectively.

\begin{tabular}{|c|c|c|c|c|c|c|}
\hline \multirow[t]{2}{*}{ Dependent Variable: } & \multicolumn{2}{|c|}{ Growth: All Customers } & \multicolumn{2}{|c|}{$\begin{array}{l}\text { Growth: Customers that Remain } \\
\text { Active } \\
\end{array}$} & \multicolumn{2}{|c|}{$\begin{array}{l}\text { Customer Remains Active } \\
\text { Dummy }\end{array}$} \\
\hline & $(1)$ & $(2)$ & (3) & (4) & (5) & (6) \\
\hline Share of Precrisis Sales on Post Shipment Terms & $\begin{array}{c}0.1687 \\
(0.0425)^{* * *}\end{array}$ & $\begin{array}{c}0.1734 \\
(0.0422)^{* * *}\end{array}$ & $\begin{array}{c}0.0999 \\
(0.0425)^{* *}\end{array}$ & $\begin{array}{c}0.0688 \\
(0.0396)^{*}\end{array}$ & $\begin{array}{c}0.1199 \\
(0.0373)^{* * *}\end{array}$ & $\begin{array}{c}0.1322 \\
(0.0341)^{* * *}\end{array}$ \\
\hline GDP Growth & $\begin{array}{c}0.5455 \\
(0.4062)\end{array}$ & $\begin{array}{c}0.5603 \\
(0.4095)\end{array}$ & $\begin{array}{c}0.6238 \\
(0.3972)\end{array}$ & $\begin{array}{c}0.5476 \\
(0.3686)\end{array}$ & $\begin{array}{c}0.1850 \\
(0.3720)\end{array}$ & $\begin{array}{c}0.2127 \\
(0.3496)\end{array}$ \\
\hline Local Currency Depreciation & $\begin{array}{l}-0.1810 \\
(0.2330)\end{array}$ & $\begin{array}{l}-0.1272 \\
(0.2337)\end{array}$ & $\begin{array}{c}0.0919 \\
(0.2238)\end{array}$ & $\begin{array}{l}-0.0057 \\
(0.2068)\end{array}$ & $\begin{array}{l}-0.2601 \\
(0.2045)\end{array}$ & $\begin{array}{l}-0.1212 \\
(0.1922)\end{array}$ \\
\hline Local Banking Crisis & $\begin{array}{c}-0.1499 \\
(0.0590) * *\end{array}$ & $\begin{array}{c}-0.1273 \\
(0.0605)^{* *}\end{array}$ & $\begin{array}{l}-0.0788 \\
(0.0613)\end{array}$ & $\begin{array}{c}-0.1197 \\
(0.0562) * *\end{array}$ & $\begin{array}{c}-0.1127 \\
(0.0523) * *\end{array}$ & $\begin{array}{l}-0.0524 \\
(0.0482)\end{array}$ \\
\hline Log of Pre-crisis Sales Value & & $\begin{array}{c}0.0512 \\
(0.0283)^{*}\end{array}$ & & $\begin{array}{c}-0.1096 \\
(0.0234)^{* * *}\end{array}$ & & $\begin{array}{c}0.1296 \\
(0.0245)^{* * *}\end{array}$ \\
\hline Log of Pre-crisis Sales Volume & & $\begin{array}{c}-0.0067 \\
(0.0250)\end{array}$ & & $\begin{array}{c}0.0136 \\
(0.0186)\end{array}$ & & $\begin{array}{l}-0.0130 \\
(0.0230)\end{array}$ \\
\hline Constant & $\begin{array}{c}-0.4607 \\
(0.0343)^{* * *}\end{array}$ & $\begin{array}{c}-1.0254 \\
(0.1495)^{* * *}\end{array}$ & $\begin{array}{c}-0.1724 \\
(0.0347)^{* * *}\end{array}$ & $\begin{array}{c}1.0987 \\
(0.1567)^{* * *}\end{array}$ & $\begin{array}{c}0.6466 \\
(0.0311)^{* * *}\end{array}$ & $\begin{array}{c}-0.8333 \\
(0.1191)^{* * *}\end{array}$ \\
\hline $\begin{array}{l}\text { No. of Obs. } \\
\text { R-Squared }\end{array}$ & $\begin{array}{c}840 \\
0.0280\end{array}$ & $\begin{array}{c}840 \\
0.0465\end{array}$ & $\begin{array}{c}569 \\
0.0151\end{array}$ & $\begin{array}{c}569 \\
0.1398\end{array}$ & $\begin{array}{c}840 \\
0.0202\end{array}$ & $\begin{array}{c}840 \\
0.1840\end{array}$ \\
\hline
\end{tabular}

